This is an author produced version of a paper published in Dalton Transactions: an international journal of inorganic chemistry. This paper has been peer-reviewed but may not include the final publisher proof-corrections or pagination.

Citation for the published paper:

Mähler, Johan; Persson, Ingmar and Herbert, Roger B. (2013) Hydration of arsenic oxyacid species. DaltonTransactions: an international journal of inorganic chemistry. Volume: 42, Number: 5, pp 1364-1377. http://dx.doi.org/10.1039/c2dt31906c.

Access to the published version may require journal subscription. Published with permission from: Royal Society of Chemistry.

Epsilon Open Archive http://epsilon.slu.se 


\title{
Hydration of Arsenic Oxyacid Species
}

\author{
Johan Mähler, ${ }^{a}$ Ingmar Persson ${ }^{a}$ and Roger Herbert ${ }^{b}$ \\ ${ }^{a}$ Department of Chemistry, Swedish University of Agricultural Sciences, P.O.Box \\ 7015, SE-750 07 Uppsala, Sweden, \\ ${ }^{\mathrm{b}}$ Department of Earth Sciences, Uppsala University, Villavägen 16, SE-752 36 \\ Uppsala, Sweden.
}

E-mail: johan.mahler@kemi.slu.se

\begin{abstract}
The bond distances in hydrated arsenic oxyacid species in aqueous solution have been studied by EXAFS spectroscopy and large angle X-ray scattering, LAXS. These results have been compared to structures in the solid state, as found in an extensive survey of available crystal structures. Protonated oxygen atoms can be distinguished with a longer As-O distance for both arsenic(V) and arsenic(III) species in the crystalline state. However, the average As-O distance for the $\mathrm{H}_{\mathrm{n}} \mathrm{AsO}_{4}{ }^{(3-\mathrm{n})-}$ species $(0 \leq \mathrm{n} \leq 3)$ remains the same. These average values are slightly shorter, ca. $0.02 \AA$, than in aqueous solution due to the hydration as determined by EXAFS and LAXS. The $\mathrm{K}$ absorption edges for arsenic(V) and arsenic(III) species are separated by $4.0 \mathrm{eV}$, and the shape of the absorption edges differs as well. Small but significant differences in the absorption edge features are seen between the neutral acids and the charged oxyacid species.

The most important arsenic species from an environmental point of view is arsenous acid, $\mathrm{As}(\mathrm{OH})_{3}$. Arsenous acid cannot be studied with the same accuracy as orthotelluric acid, due to a relatively low solubility of $\mathrm{As}_{2} \mathrm{O}_{3}(\mathrm{~s})$ in neutral to acidic aqueous solution. In addition to arsenous acid, we have used orthotelluric acid, $\mathrm{Te}(\mathrm{OH})_{6}$, for comparison with arsenous acid and for detailed studies of the hydration of covalently bound hydroxo groups. The results from the DDIR studies support the assignment of $\mathrm{As}(\mathrm{OH})_{3}$ as a weak structure maker analogous to $\mathrm{Te}(\mathrm{OH})_{6}$, both being neutral weak oxyacids.
\end{abstract}




\section{Introduction}

The occurrence of dissolved inorganic arsenic compounds in ground water used for human consumption is a problem in large parts of the world, and is especially alarming in a number of developing countries without efficient techniques for water cleaning. ${ }^{1}$ It is geological sources rather than anthropological ones that are causing the problems, ${ }^{2}$ but increased water utilization causes increased arsenic mobilization in ground waters. The use of phosphorus fertilizers may contribute to mobilization of arsenic both by direct desorption of arsenate by competing phosphate, and via an increased growth of sediment biota. ${ }^{3}$ Arsenic occurs in natural waters as either arsenic(V) or arsenic(III). The inorganic forms of the pentavalent species are deprotonated forms of arsenic acid, $\mathrm{H}_{3} \mathrm{AsO}_{4}$, a relatively strong weak acid, ${ }^{4}$ while the most common inorganic trivalent species is the neutral arsenous acid, $\mathrm{As}(\mathrm{OH})_{3}{ }^{5}$ The relationship between intramolecular distances and degree of protonation can easily be studied with crystalline material but in principle impossible to perform in solution. It is of fundamental interest to study how the hydration affects the structure of anions in aqueous solution in comparison to their structure in the solid state as these weakly hydrated species more or less never crystallize with complete hydrations shells. The hydration is furthermore important for the reactivity as it will decrease with increasing hydration. A thorough review concerning reactivity and biological activity of arsenic compounds was published 20 years ago. ${ }^{6}$

\section{The arsenic acid system}

Arsenic acid, $\mathrm{O}=\mathrm{As}(\mathrm{OH})_{3}$, with the acid dissociation constants $\mathrm{p} K_{\mathrm{a} 1}=2.25, \mathrm{p} K_{\mathrm{a} 2}=7.05$ and $\mathrm{p} K_{\mathrm{a} 3}=11.58,{ }^{7}$ is an acid of similar strength as the analogous phosphoric acid, $\mathrm{O}=\mathrm{P}(\mathrm{OH})_{3}$. A very similar hydration behavior between these systems is expected. ${ }^{8}$ Arsenic(V) (arsenate) species are anionic in natural drinking water, where $\mathrm{pH}$ frequently ranges from 6.5 to 8.5 . $^{9}$ The basic structure of the arsenate ions is a central As atom binding to four oxygens in a regular or near tetrahedral fashion. The arsenic acid system is shown in Figure 1, illustrated with Hydra-Medusa. ${ }^{10,11}$ An infrared spectroscopy study by Myneni showed that protonation distorts the symmetry of the $\mathrm{AsO}_{4}$-tetrahedron substantially. ${ }^{12}$ Manning et al. used EXAFS to report a mean As-O distance of $1.69 \AA$ for arsenate in solution, however without reporting the origin of the arsenate, the $\mathrm{pH}$ of the solution or the predicted arsenic(V) species. ${ }^{13}$ Several authors have used EXAFS to study arsenate species adsorbed to mineral surfaces, ${ }^{13-20}$ and obtained mean As-O distances are frequently in the same range as reported by Manning for free arsenate. As K edge XANES spectra for a number of solvated arsenic species have previously been reported by Smith, ${ }^{21}$ and others. ${ }^{13,22-24}$ A QMCF MD simulation of the $\mathrm{HAsO}_{4}{ }^{2-}$ ion by Bhattacharjee et al. supports the results from the experimental studies. ${ }^{25}$

In biological systems, arsenate may be methylated to form monomethyl and dimethyl compounds. ${ }^{26}$ Methylation of inorganic arsenic is important in the metabolic removal of the element. ${ }^{6}$ Monomethyl arsenic acid (MMA) can dissociate two protons with $\mathrm{p} K_{\mathrm{a} 1}=3.6$ and $\mathrm{pK}_{\mathrm{a} 2}=8.2 .^{27}$ Dimethyl arsenic acid (DMA) has a $\mathrm{p} K_{\mathrm{a}}$ value of $6.2 .^{27}$ 


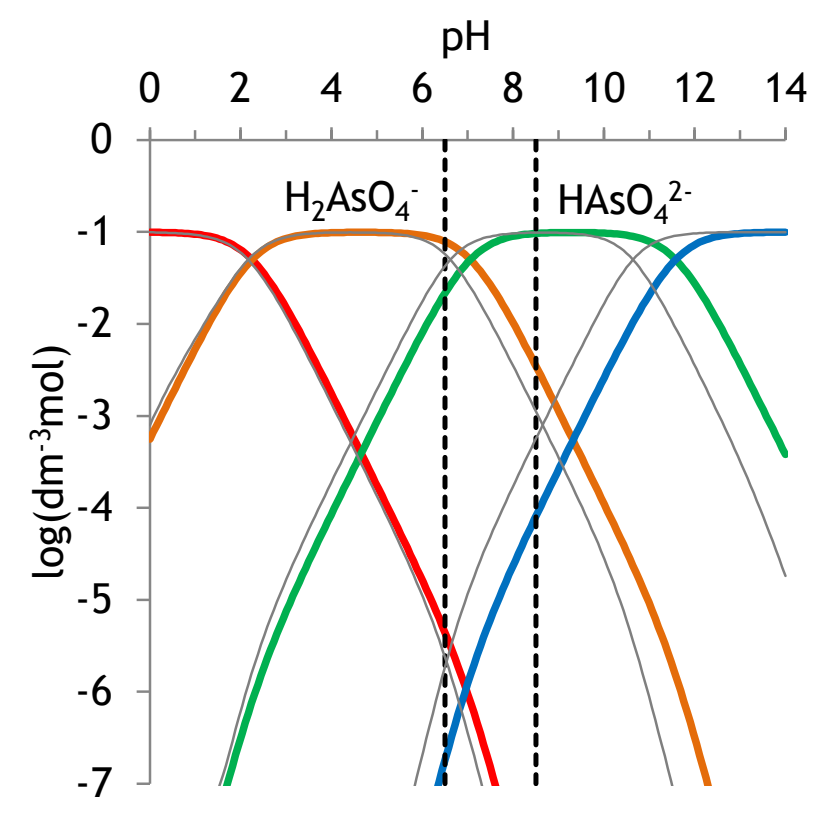

Figure 1: Logarithmic equilibrium diagram for $\operatorname{arsenic}(\mathrm{V})$ in aqueous solution for the ionic strength $I=0, \mathrm{~T}=$ $298 \mathrm{~K}, C_{\mathrm{As}(\mathrm{V})}=0.1 \mathrm{M}$, with acid dissociation constants from reference 7; red $-\mathrm{H}_{3} \mathrm{AsO}_{4}$; orange $-\mathrm{H}_{2} \mathrm{AsO}_{4}{ }^{-}$; green $-\mathrm{HAsO}_{4}{ }^{2-}$; blue $-\mathrm{AsO}_{4}{ }^{3-}$. The $\mathrm{pH}$ range most relevant from a drinking water perspective is delimited by dashed lines. Thin grey lines represent the case when ionic strength in the solution is calculated from ionic content, $\mathrm{pH}$ being adjusted with hydrochloric acid and sodium hydroxide, and are valid for the concentrated solutions used in the EXAFS studies. The WHO recommendation for acceptable arsenic levels in drinking water is $10^{-6.9} \mathrm{~mol}^{\cdot} \cdot \mathrm{dm}^{-3}$.

\section{Arsenous acid system}

Arsenous acid, $\mathrm{As}(\mathrm{OH})_{3}$, is formed by dissolving arsenic(III) oxide or salts containing the linear meta-arsenite(III) unit, $\left[\mathrm{AsO}_{2}{ }^{-}\right]_{\mathrm{n}}$, in water. However, the pure acid has not been isolated. ${ }^{4} \mathrm{The} \mathrm{As}(\mathrm{OH})_{3}$ unit have $C_{3 \mathrm{v}}$ symmetry with a lone electron-pair along the three-fold axis. ${ }^{28}$ The distribution of arsenous acid species with different degrees of protonation is shown in Figure $2,{ }^{10,11}$ using $\mathrm{p} K_{\mathrm{a} 1}=9.25, \mathrm{p} K_{\mathrm{a} 2}=12.13$ and $\mathrm{p} K_{\mathrm{a} 3}=13.4,{ }^{29,30}$ hence placing $\mathrm{As}(\mathrm{OH})_{3}$ as a very weak acid. It can be seen that the neutral molecule $\mathrm{As}(\mathrm{OH})_{3}$ dominates over a wide range of $\mathrm{pH}$. Testemale et al. performed an X-ray absorption investigation on $\mathrm{As}(\mathrm{OH})_{3}$ in aqueous solution, confirming the covalence within the As-O bonds and showing that a temperature increase opens up the O-As-O angles, following a decrease in hydrogen bonding strength. ${ }^{31}$ A computer simulation by Hernandez-Cobos et al. predicts that $\mathrm{As}(\mathrm{OH})_{3}$ hydration occurs mainly at the hydroxyl groups, while the lone pair on arsenic(III) rather being surrounded by a clathrate like structure, ${ }^{32}$ in a similar way as recently described for the hydrated sulfite ion. ${ }^{33}$ It has been proposed that this type of hydration is the reason why $\mathrm{As}(\mathrm{OH})_{3}$ has the ability to pass through aqua-glyceroporines-membrane proteins for the transportation of glycerol and urea. ${ }^{32} \mathrm{~A}$ computer simulation of $\mathrm{AsO}(\mathrm{OH})_{2}{ }^{-}$by Tossel predicts one As-O distance of $1.647 \AA$ and two distances of $1.815 \AA$, mean $1.759 \AA$, while a simulation of $\mathrm{AsO}_{2} \mathrm{OH}^{2-}$ did predict one longer distance of $1.940 \AA$ and two shorter averaging at $1.684 \AA$, mean $1.769 \AA$, and As-O-As angles of $97-99^{\circ} .{ }^{34}$ The same author also opens up the possibility for the formation of $\mathrm{As}_{4} \mathrm{O}_{6}$ or $\mathrm{As}_{3} \mathrm{O}_{3}(\mathrm{OH})_{3}$ molecules at high concentrations. ${ }^{34}$ 


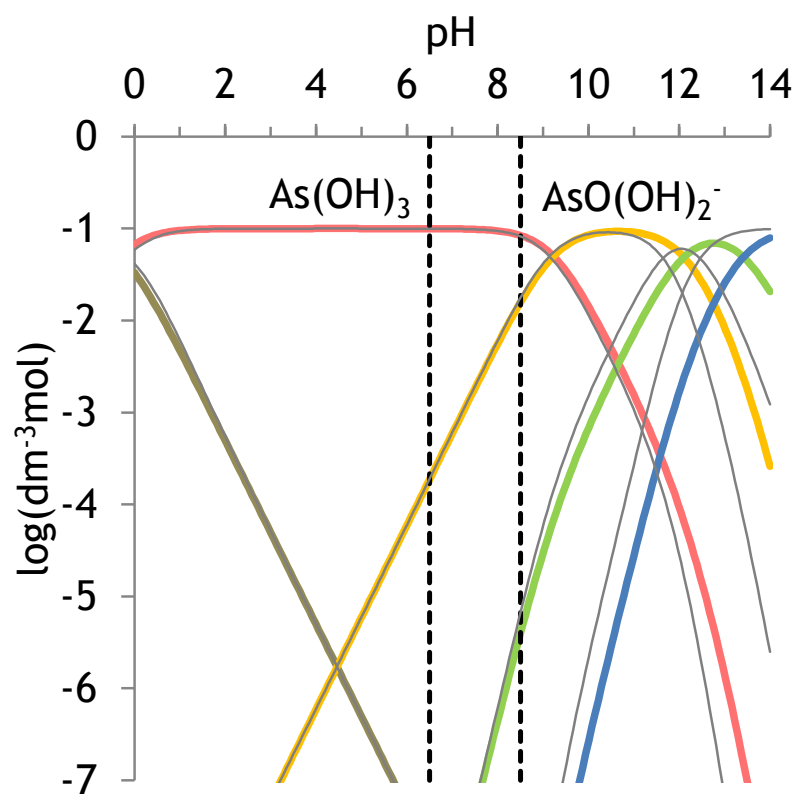

Figure 2: Logarithmic equilibrium diagram for arsenic(III) in aqueous solution, $25^{\circ} \mathrm{C}$, ionic strength, $I=0, T=$ $298 \mathrm{~K}, C_{\mathrm{As}(\mathrm{III})}=0.1 \mathrm{M}$; brown - $\mathrm{As}(\mathrm{OH})_{2}{ }^{+}$; red - $\mathrm{As}(\mathrm{OH})_{3}$; light orange - $\mathrm{AsO}(\mathrm{OH})_{2}{ }^{-}$; light green - $\mathrm{AsO}_{2} \mathrm{OH}^{2-}$; light blue $-\mathrm{AsO}_{3}{ }^{3-}$. The $\mathrm{pH}$ range most relevant from a drinking water perspective is delimited by dashed lines. Thin grey lines represent the case when ionic strength in the solution is calculated from ionic content, $\mathrm{pH}$ being adjusted with hydrochloric acid and sodium hydroxide, and are valid for the concentrated solutions used in the EXAFS studies. The WHO recommendation for acceptable arsenic levels in drinking water is $10^{-6.9} \mathrm{~mol}^{\cdot} \cdot \mathrm{dm}^{-3}$. The solid phase $\mathrm{As}_{2} \mathrm{O}_{3}(\mathrm{~s})$ precipitates at somewhat higher concentrations than shown and at $\mathrm{pH}$ values below the $\mathrm{p} K_{\mathrm{a}}$ value of arsenous acid.

\section{Orthotelluric acid system}

As a non-charged oxoacid molecule at neutral $\mathrm{pH}$, orthotelluric acid, $\mathrm{Te}(\mathrm{OH})_{6}$, is a possible model compound for the study of the hydration of covalently bound $\mathrm{OH}$ groups. Being a neutral weakly acidic species with covalently bound hydroxo groups, it is expected that the hydroxo groups of the weak acids $\mathrm{Te}(\mathrm{OH})_{6}$ and $\mathrm{As}(\mathrm{OH})_{3}$ interact with water in a similar way even though it is not known to what extent the lone pair of arsenous acid affects its hydration. Orthotelluric acid is thought to persist in aqueous solution without any significant deprotonation over a wide $\mathrm{pH}$ range; as shown by the high $\mathrm{p} K_{\mathrm{a}}$ values, $\mathrm{p} K_{\mathrm{a} 1}=7.70$ and $K_{\mathrm{a} 2}=11.0 .{ }^{35}$ Orthotelluric acid is a much weaker acid than the acids of sulfur(VI) and selenium(VI), and is not known to form tetrahedral units analogous to sulfate $\left(\mathrm{SO}_{4}{ }^{2-}\right)$ and selenate $\left(\mathrm{SeO}_{4}{ }^{2-}\right)$ in aqueous solution. ${ }^{36}$ In combination with the high solubility in water, ${ }^{37}$ it enables the preparation of solutions with high concentrations of the neutral $\mathrm{Te}(\mathrm{OH})_{6}$ acid. From nine reported crystal structures of $\mathrm{Te}(\mathrm{OH})_{6}$, the mean Te-O bond distance is $1.916 \pm 0.004 \AA .^{38-46}$ These structures have a mean Te-O-H angle of $112^{\circ} \pm 6^{\circ}$ and a mean O-H distance of $0.84 \AA \pm 0.09 \AA$. The Te-O distance has also been confirmed by solid phase EXAFS. ${ }^{47}$ The last two parameters are very uncertain as the position of hydrogen atoms can only be determined with limited accuracy. A large angle X-ray scattering investigation of $\mathrm{Te}(\mathrm{OH})_{6}$ in aqueous solution reported a mean Te-O bond distance of $1.935 \AA$ with twelve hydrogen bonded water molecules in the first hydration sphere. ${ }^{48} \mathrm{~A}$ review by Dutton and Cooper treats the properties of telluric oxyacids in detail. ${ }^{49}$ 


\section{Aims}

The aims of this work are to determine the structures of the hydrated inorganic arsenite(III) and arsenate(V) ions in aqueous solution by means of extended X-ray absorption fine structure, EXAFS, and by large angle X-ray scattering, LAXS, and to ascertain the hydrogen bond strength of the water molecules hydrogen-bound to arsenous and orthotelluric acid in aqueous solution with the double difference IR technique. A literature study of reported crystal structures of arsenate and arsenite compounds has been performed and the As-O bond distances are compared to the experimental data in solution. In addition to the arsenic species, this work will also discuss the structure and hydrogen bonding of the hydrated orthotelluric acid, $\mathrm{Te}(\mathrm{OH})_{6}$, which share several features with the arsenous acid, $\operatorname{As}(\mathrm{OH})_{3}$.

\section{Experimental}

\section{Chemicals}

Heavy water, $\mathrm{D}_{2} \mathrm{O}$, (Aldrich, 99.96 atom\% purity) was used for the DDIR experiments. Arsenic trioxide, $\mathrm{As}_{2} \mathrm{O}_{3}$, (Merck) was used for the DDIR experiments on $\mathrm{As}(\mathrm{OH})_{3}$. For the other solutions containing arsenic(III), sodium metaarsenite, $\mathrm{NaAsO}_{2}(\mathrm{Labkemi}$, analytical grade) was used. Disodium hydrogen arsenate heptahydrate, $\mathrm{Na}_{2} \mathrm{HAsO}_{4} \cdot 7 \mathrm{H}_{2} \mathrm{O}$, (SigmaAldrich, $>99.97 \%$ ) was used for all arsenic(V) solutions. Disodium methylarsenate, $\mathrm{Na}_{2} \mathrm{CH}_{3} \mathrm{AsO}_{3}$ (Sigma Aldrich), and dimethylarsinic acid, $\left(\mathrm{CH}_{3}\right)_{2} \mathrm{AsO}(\mathrm{OH})$, (Sigma Aldrich) were used as purchased. Solid orthotelluric acid, $\mathrm{Te}(\mathrm{OH})_{6}$, (BDH Chemicals Ltd, 99.5\%), was used to prepare the solutions of orthotelluric acid.

\section{Solutions}

The solutions for the EXAFS and LAXS measurements were prepared by weighing $\mathrm{Na}_{2} \mathrm{HAsO}_{4} \cdot 7 \mathrm{H}_{2} \mathrm{O}$ and $\mathrm{NaAsO}_{2}$ or $\mathrm{As}_{2} \mathrm{O}_{3}$ which were dissolved in water, and appropriate amounts of sodium hydroxide or nitric acid were added. Weighed amounts of disodium methylarsenate and dimethylarsenic acid were dissolved in water without any $\mathrm{pH}$ adjustment. The composition and $\mathrm{pH}$ of the arsenic oxyacid solutions studied by EXAFS and LAXS are summarized in Table 1.

The $\mathrm{As}(\mathrm{OH})_{3}$ concentrations used for double difference IR measurements were 0.1273 , $0.1100,0.0900,0.0704$ and $0.0503 \mathrm{~mol} \cdot \mathrm{dm}^{-3}$ in $8 \% \mathrm{HDO}$, while corresponding concentrations in water were $0.1272,0.1098,0.0904,0.0701$ and $0.0502 \mathrm{~mol} \cdot \mathrm{dm}^{-3}$. Density measurements were performed with an Anton Paar DMA 4100M densitometer, utilizing the oscillation Utube method.

The concentration of the aqueous solutions of orthotelluric acid used in the LAXS experiment was $2.0003 \mathrm{~mol} \cdot \mathrm{dm}^{-3}$, the density $1.340 \mathrm{~g} \cdot \mathrm{cm}^{-3}$ and the absorption coefficient $10.251 \mathrm{~cm}^{-1}$. The $\mathrm{Te}(\mathrm{OH})_{6}$ concentrations used for double difference IR measurements were 0.9994, 0.8873, 0.7994, 0,7407, 0.5996, 0.5002, 0.3988, 0.2958, 0.1991 and $0.0994 \mathrm{~mol} \cdot \mathrm{dm}^{-3}$ for the HDO solutions. The corresponding $\mathrm{H}_{2} \mathrm{O}$ solutions were $0.9993,0.8988,0.7974$, $0.7410,0.5988,0.5005,0.3987,0.2997,0.1995$ and $0.0996 \mathrm{~mol} \cdot \mathrm{dm}^{-3}$. 
Table 1. Concentrations $\left(\mathrm{mol} \cdot \mathrm{dm}^{-3}\right)$ of the aqueous solutions studied by LAXS $(L)$ and EXAFS $(E)$ including their densities, $\rho$, linear absorption coefficients, $\mu$, and label $x s$ denotes excess solvent.

\begin{tabular}{lcccccccc}
\hline Sample & {$\left[\mathrm{As}^{\mathrm{III}}\right]$} & {$\left[\mathrm{As}^{\mathrm{V}}\right]$} & {$\left[\mathrm{Na}^{+}\right]$} & {$\left[\mathrm{H}_{2} \mathrm{O}\right]$} & $\rho / \mathrm{g} \cdot \mathrm{cm}^{-3}$ & $\mu / \mathrm{cm}^{-1}$ & $\mathrm{pH}$ & Method \\
\hline $\mathrm{As}(\mathrm{OH})_{3}$ & 0.1272 & & & Xs & & & 3.15 & $\mathrm{E}$ \\
$\mathrm{AsO}(\mathrm{OH})_{2}{ }^{-}$, & 1.5041 & & 1.7475 & 53.243 & 1.160 & 9.203 & 10.6 & $\mathrm{~L}$ \\
$\mathrm{AsO}(\mathrm{OH})_{2}{ }^{-}$ & 0.1227 & & 0.1227 & xs & & & 10.55 & $\mathrm{E}$ \\
$\mathrm{AsO}_{3}{ }^{3-}$ & 0.1201 & & 0.4310 & xs & & & 13.32 & $\mathrm{E}$ \\
$\mathrm{H}_{3} \mathrm{AsO}_{4}$ & & 0.0989 & 0.1978 & xs & & & 0.90 & $\mathrm{E}$ \\
$\mathrm{H}_{2} \mathrm{AsO}_{4}{ }^{-}$ & 0.0988 & 0.1976 & xs & & & 4.46 & $\mathrm{E}$ \\
$\mathrm{HAsO}_{4}{ }^{2-}$ & 0.0996 & 0.1992 & xs & & & 9.02 & E \\
$\mathrm{AsO}_{4}{ }^{3-}$ & 1.5006 & 4.5018 & 52.151 & 1.251 & 9.427 & 12.8 & $\mathrm{~L}$ \\
$\mathrm{AsO}_{4}{ }^{3-}$ & 0.1001 & 0.7435 & xs & & & 13.59 & E \\
$\mathrm{CH}_{3} \mathrm{AsO}(\mathrm{O})^{2-}$ & 0.09 & 0.18 & xs & & & 10.31 & E \\
$\left(\mathrm{CH}_{3}\right)_{2} \mathrm{AsO}(\mathrm{OH})$ & 0.10 & & xs & & & 4.08 & E \\
\hline
\end{tabular}

\section{XAFS}

K-edge X-ray absorption spectra of the aqueous arsenic solutions listed in Table 1 were collected at the wiggler beam-line I811 at the MAX-lab facility at Lund University, Sweden. The facility operated at $1.5 \mathrm{GeV}$ and a maximum current of $250 \mathrm{~mA}$. A double crystal monochromator, $\mathrm{Si}(311)$ or $\mathrm{Si}(111)$, was used. The second monochromator crystal was detuned to $40 \%$ of maximum intensity at the end of the scans to minimize higher harmonics. All spectra were energy calibrated versus elemental arsenic, ground into a fine powder and mixed with BN, by assigning the first inflection point of the $\mathrm{K}$ edge to $11867.0 \mathrm{eV}^{50}$ The solutions were contained in cells made of a Teflon spacer and $6 \mu \mathrm{m}$ polypropylene film held together with a titanium frame. The experiments were performed in transmission mode at the As K edge using gas filled ion chambers. Data treatment was performed with the computer program packages EXAFSPAK ${ }^{51}$ and GNXAS. ${ }^{52} \mathrm{Ab}_{\text {initio calculated phase and amplitude }}$ parameters, used by the EXAFSPAK program, were computed by the FEFF7 program. ${ }^{53}$

\section{Large Angle X-ray Scattering}

The scattering of $\mathrm{MoK}_{\alpha} \mathrm{X}$-ray radiation, $\lambda=0.7107 \AA$, from the free surface of the aqueous solutions listed in Table 1 was measured in a large angle $\Theta-\Theta$ goniometer described elsewhere. ${ }^{54}$ The solution was contained in a Teflon cup filled until a positive meniscus was observed generating a flat surface in the irradiated region. The container was placed inside an air-tight radiation shield with beryllium windows. The scattered radiation was monochromatized using a $\operatorname{LiF}(200)$ single crystal focusing monochromator. The scattering was determined at 450 steps in the angle range of $0.5<\Theta<65^{\circ}$, where the scattering angle is $2 \Theta$. At each angle $100,000 \mathrm{X}$-ray quanta were counted, and the entire angle range was scanned twice corresponding to a statistical error of about $0.3 \%$. The divergence of the Xrays was defined through combination of divergence-collecting-focal slits of $1 / 4^{0}-1 / 2-0.1 \mathrm{~mm}$ or $1^{\circ}-2^{\circ}-0.2 \mathrm{~mm}$ depending angle range. Three different $\Theta$-regions where scanned to get a suitable counting rate and change in angle, with overlapping regions to enable scaling of the data. The data collection and treatment are described in detail elsewhere. ${ }^{54}$ All data treatment 
was carried out using the KURVLR program, ${ }^{55}$ and the structural parameters in the theoretical model where refined by minimizing $U=w(s) \Sigma s^{2}\left[i_{\text {exp }}(s)-i_{\text {calc }}(s)\right]^{2}$ using the STEPLR program. ${ }^{56}$ The experimental data was normalized to a stoichiometric unit containing one central atom of arsenic or tellurium, using the scattering factors $f$ for neutral atoms, including corrections for anomalous dispersion, $\Delta f^{\prime}$ and $\Delta f^{\prime \prime},{ }^{57-59}$ and multiple scattering events. Removal of spurious non-physical peaks below $1.2 \AA$ was performed with a Fourier back-transformation procedure and this improves alignment of the experimental structure-dependent intensity function $i_{\exp }(s) .{ }^{60}$

\section{Crystal structure database search}

Reported crystal structures containing individual units of $\mathrm{H}_{3} \mathrm{AsO}_{4}, \mathrm{H}_{2} \mathrm{AsO}_{4}{ }^{-}, \mathrm{HAsO}_{4}{ }^{2-}$ and $\mathrm{AsO}_{4}{ }^{3-}$ were collected from the Cambridge Structural Database and the Inorganic Crystal Structure Database. ${ }^{61,62}$ In order for the different structures to be potentially representative for comparison with hydrated species in aqueous solution, only those in which arsenate oxygen atoms binding to neutral species or univalent ligand atoms were considered. Species in which $\mathrm{Ag}^{+}$or $\mathrm{Tl}^{+}$bind directly to the arsenate oxygen atoms have not been included, as the soft character of these metal ions may alter the electron distribution and thereby their structure. Finally, those structures unable to pass a recursive Grubb's test for outliers on the 0.01 level have been excluded in the calculations. ${ }^{63,64}$ These outliers are still presented together with included structures in Tables S1-S5. Only one structure of $\mathrm{AsO}_{2} \mathrm{OH}^{2-}$ fitted the same criteria when it came to arsenic(III) species. $\mathrm{As}(\mathrm{OH})_{3}$ does not crystallize without transforming to other species such as $\mathrm{AsO}_{2}^{-}$or $\mathrm{As}_{2} \mathrm{O}_{3}$.

In addition to the inorganic species, a number of organic arsenic( $\mathrm{V})$ compounds of the forms $\mathrm{RAsO}(\mathrm{OH})_{2}$ and $\mathrm{R}_{2} \mathrm{AsOOH}$ are presented in Tables S6-S7.

\section{Double difference infrared spectroscopy}

A Perkin-Elmer Spectrum 100 FT-IR spectrometer was used for the double difference IR measurements. Windows, sample holder and temperature controller were supplied by Pike Technologies. Data analysis was performed with the spectroscopy software GRAMS/AI 8.0 from Thermo Electron Corporation and its add-in Razortools from Spectrumsquare. The additional algorithm Yanuz from the Stangret group in Gdansk has been used to find the derivative with respect to concentration. The sample was kept between two $\mathrm{CaF}_{2}$ windows separated by a Teflon spacer. The path length was interferrometrically determined to 32.720 $\mu \mathrm{m}$. The temperature was kept at $25 \pm 0.1^{\circ} \mathrm{C}$ by an electrically heated liquid cell temperature controller from Pike Technologies. The beam diameter was set to $3 \mathrm{~mm}$, and 256 scans were collected in the range $3500-900 \mathrm{~cm}^{-1}$ with a resolution of $4 \mathrm{~cm}^{-1}$. Spectral treatment was performed in accordance with a method developed at Uppsala University. ${ }^{65}$ To summarize, a raw spectrum from a sample with a certain concentration of solute in water is subtracted from a spectrum with an equal concentration of solute in $\sim 8 \%$ HDO with necessary corrections for $\mathrm{H}_{2} \mathrm{O} / \mathrm{HDO}$ concentrations, scaling and offset. Thereafter, the influence of bulk water is subtracted in order to obtain an affected spectrum, representing water molecules different from the aqueous bulk, thus being those affected by the solute. Bulk water removal is a critical step which is performed with an algorithm developed by the Stangret group. ${ }^{66,67}$ In short, an affected spectrum extrapolated to infinite dilution $\left(\varepsilon_{\mathrm{a}}\right)$ can be produced from a 
derivative with respect to concentration, according to equation 1. Other parameters are the bulk water spectrum $\left(\varepsilon_{\mathrm{b}}\right)$, the mean molar mass of the solvent $\mathrm{H}_{2} \mathrm{O} / \mathrm{HDO}(\mathrm{M})$ and the affected number $N .^{67}$

$$
\varepsilon_{a}=\frac{1}{N M}\left(\frac{\partial s}{\partial m}\right)+\varepsilon_{b}
$$

The main advantage of the double difference technique is that information can be obtained about the hydrogen bonding around the solute species, the degree of this interference depending on the peak(s) location in the affected spectrum. A strong intra molecular O-D bond causes a weak O-D $\cdots$ O hydrogen bond and the other way round. Sufficiently strong hydrogen bonds will increase the order in the water matrix (structure making) while weak ones may decrease it (structure breaking). ${ }^{6}$ An O-D stretch located at higher wave numbers than $2509 \mathrm{~cm}^{-1}$ indicate structure breaking while an O-D stretch located at lower wave numbers than $2509 \mathrm{~cm}^{-1}$ originate from a structure making ion or molecule. Hydrogen bonding and its relationship with affected peaks are discussed in more detail elsewhere. ${ }^{69}$

\section{Results and discussion}

\section{Crystal structure database search}

In order to obtain a detailed view of the As-O bond distances in arsenic(III) and $\operatorname{arsenic}(\mathrm{V})$ species, a survey of the structures of inorganic arsenates and arsenites has been made, and the individual references are given in the supporting material section, Tables S1 and S3-S5. Five structures have been excluded as they failed to pass a recursive Grubbs statistical test for outliers on the 0.01 level for two tails, but included in Tables S3-S5.

Reported crystal structures are often lacking information about the positions of the hydrogen atom(s). However, it is possible to conclude whether an oxygen binds a hydrogen atom or not from the As-O bond length. The As-O bond distances of protonated arsenic oxygens, As-OH, are significantly longer than those of unprotonated ones, formally As- $\mathrm{O}^{-}$or $\mathrm{As}=\mathrm{O}$. In Figures 3-6, all four oxygen distances of each of the $\operatorname{arsenic}(\mathrm{V})$ species $\mathrm{AsO}_{4}{ }^{3-}$, $\mathrm{HAsO}_{4}{ }^{2-}, \mathrm{H}_{2} \mathrm{AsO}_{4}{ }^{-}$and $\mathrm{H}_{3} \mathrm{AsO}_{4}$ have been plotted, respectively. Starting with $\mathrm{AsO}_{4}{ }^{3-}$, all distances are related with a linear relationship, as expected for a symmetrical ion, Figure 3. For $\mathrm{HAsO}_{4}{ }^{2-}$ it can be seen that the longest distance deviates markedly from the linear relationship connecting the three shortest distances, Figure 4. The As-O bond distance to the oxygen with a proton is significantly longer, ca. $0.07 \AA$, or $0.05 \AA$ longer than would be expected from the linear trend. It is also seen that the standard deviations for determined distances are considerably smaller than for the completely symmetrical $\mathrm{AsO}_{4}{ }^{3-}$ ion, Figure 3 . For the $\mathrm{H}_{2} \mathrm{AsO}_{4}{ }^{-}$ion the break from linearity occurs after two distances giving separate relationships for shorter-binding and longer-binding oxygen atoms as expected. The difference between the linear trends is 0.03-0.04 $\AA$. Most of the crystallographic studies also assign the longer distances to protonated oxygen atoms. As in the case of $\mathrm{HAsO}_{4}{ }^{2-}$ the standard deviation for each distance is rather small. Corresponding features can also be seen for arsenic acid, Figure 6, although not as clearly as for the other species. The standard deviations are larger than for both $\mathrm{H}_{2} \mathrm{AsO}_{4}{ }^{-}$and $\mathrm{HAsO}_{4}{ }^{2-}$. 
As the intramolecular distances are sorted from shortest to longest, a positive slope will be obtained. It is however rather small for the arsenate ion. It can also be seen that the slope of the trend line connecting unprotonated oxygen distances increases with increasing protonation, going from $0.005\left(\mathrm{AsO}_{4}{ }^{3-}\right)$, through $0.008\left(\mathrm{HAsO}_{4}{ }^{2-}\right)$ to $0.012\left(\mathrm{H}_{2} \mathrm{AsO}_{4}{ }^{-}\right)$(Figures 3-5). A similar relationship can be seen for the slope of the trend-line connecting protonated oxygen atoms, going from $0.007\left(\mathrm{H}_{2} \mathrm{AsO}_{4}{ }^{-}\right)$to $0.016\left(\mathrm{H}_{3} \mathrm{AsO}_{4}\right)$ (Figures 5-6). In a solution, there is no reason to expect anything but two distinct distance levels for these species. Levels valid for comparison with solution can be approximated by defining the long level as mean distance \# 4 for $\mathrm{HAsO}_{4}{ }^{2-}$, distances \# 3 and 4 for $\mathrm{H}_{2} \mathrm{AsO}_{4}{ }^{-}$and distances \# 2, 3 and 4 for $\mathrm{H}_{3} \mathrm{AsO}_{4}$. Remaining distances fall on the short distance level.

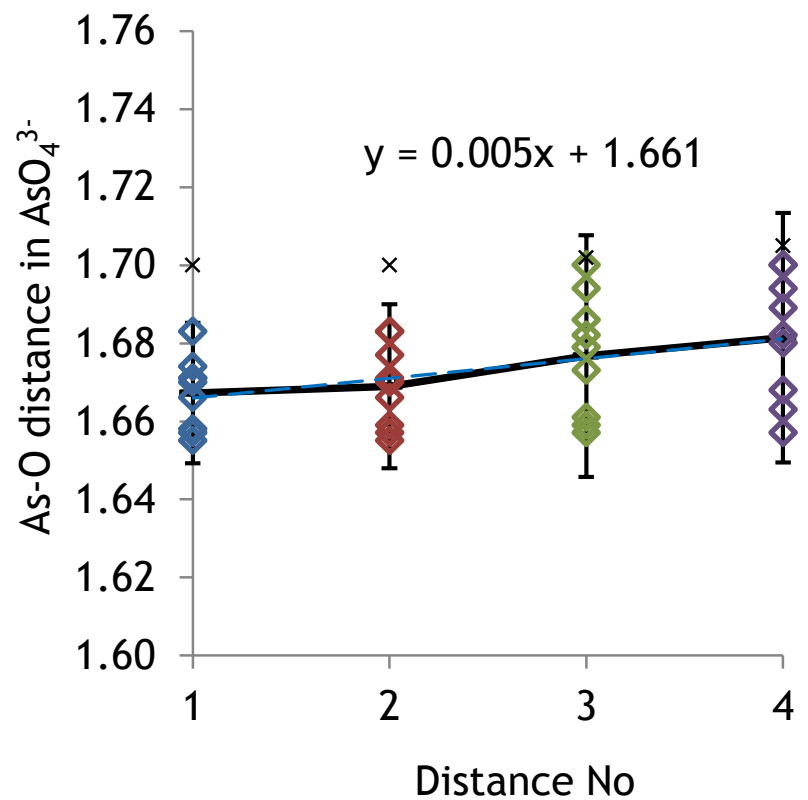

Figure 3: The four As-O distances obtained from nine crystal structures containing an $\mathrm{AsO}_{4}{ }^{3-}$ ion. Shortest distance (blue), second shortest (red), second longest (green) and longest distance (purple) are related as shown by the linear equation (dashed blue line). In addition, one structure failing Grubbs statistical test for outliers is shown as crosses. All distances in this structure have been excluded as some failed the Grubbs test. The black line connects average values for each distance.

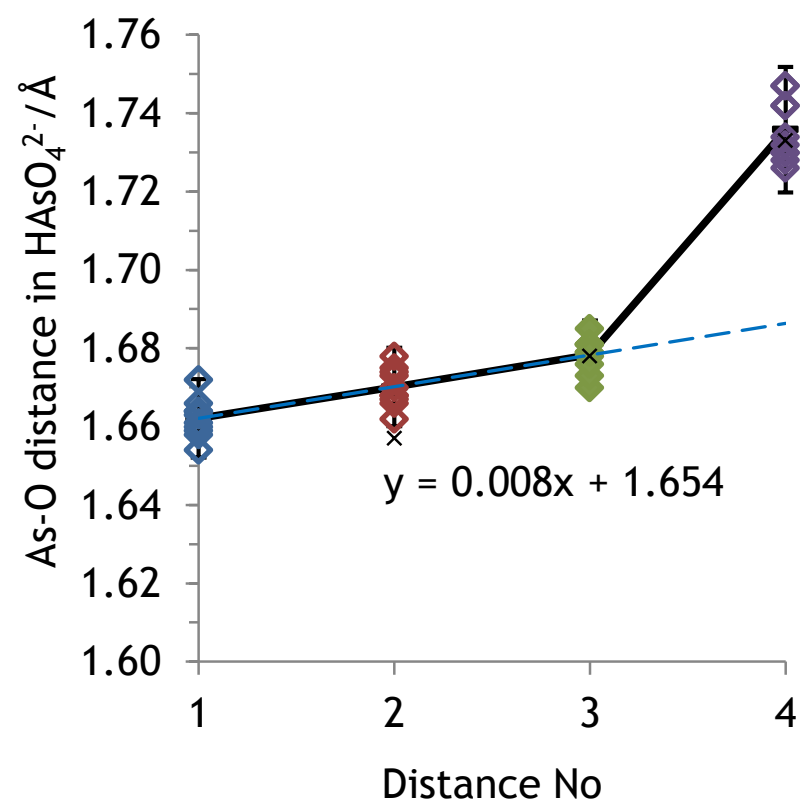

Figure 4: The four As-O distances obtained from ten crystal structures containing an $\mathrm{HAsO}_{4}{ }^{2-}$ ion. Shortest distance (blue), second shortest (red), third shortest (green) are related as shown by the linear equation (dashed blue line). The longest distance (purple) deviates from this relationship. In addition, one structure failing Grubbs statistical test for outliers is shown as crosses. All distances in this structure have been excluded as the first one failed Grubbs test with a value of $1.599 \AA$. The black line connects average values for each distance. 

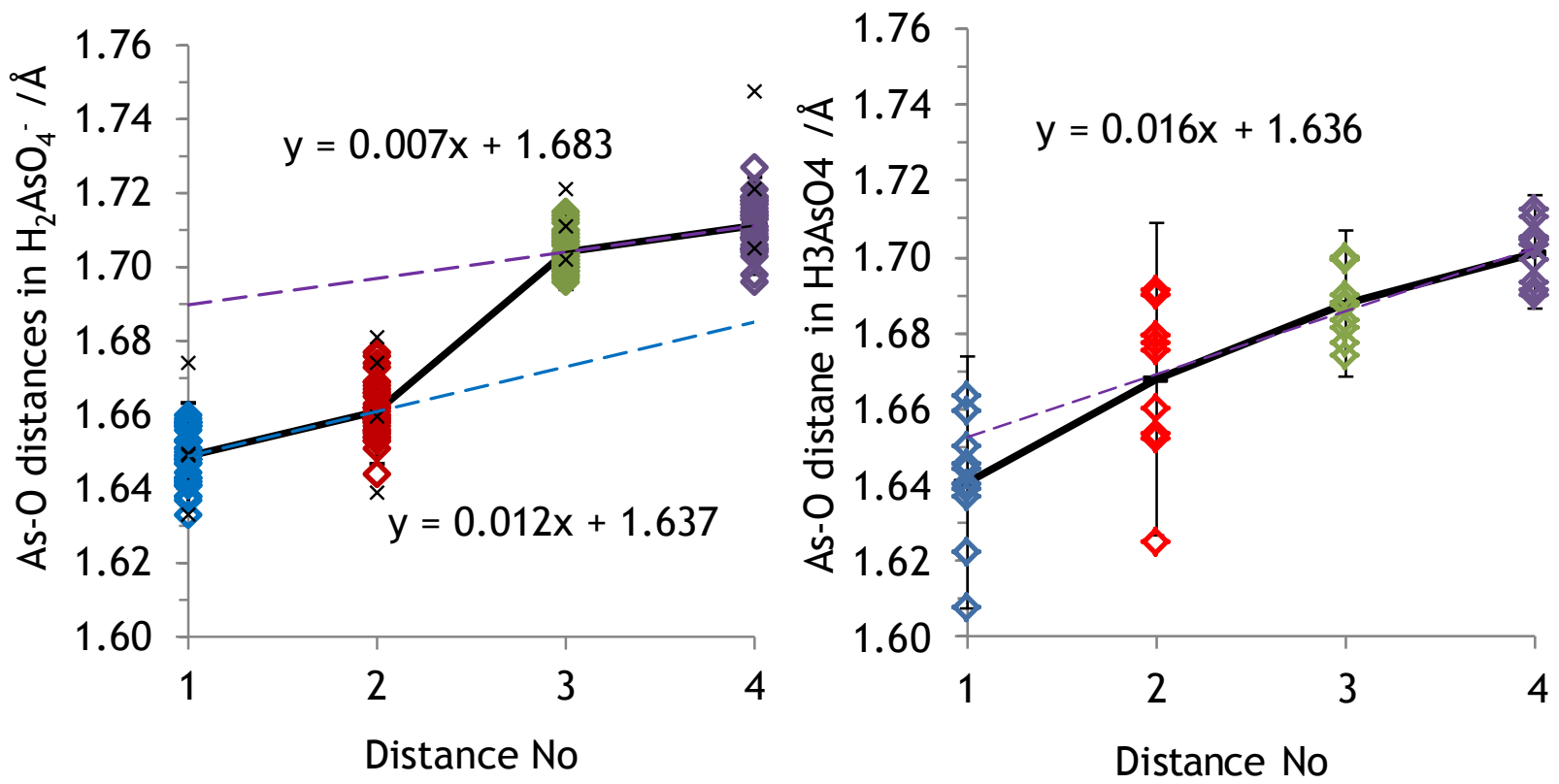

Figure 5: The four As-O distances obtained from 38 crystal structures containing an $\mathrm{H}_{2} \mathrm{AsO}_{4}{ }^{-}$ion. Shortest distance (blue) and second shortest (red) are related as shown by the lower linear equation (dashed blue line). The second longest (green) and longest (purple) distances are related as shown by the upper linear equation (dashed purple line). In addition, four structures failing Grubbs statistical test for outliers are shown as crosses. All of the distances in these structures have been excluded as at least one failed the Grubbs test. The black line connects average values for each distance.

Figure 6: The four As-O distances obtained from ten crystal structures containing a $\mathrm{H}_{3} \mathrm{AsO}_{4}$ molecule. The shortest distance is shown with blue diamonds. The third longest (red), second longest (green) and longest distances are related as shown by the linear equation (dashed purple line). The black line connects average values for each distance.

In Figure 7, short and long distances are plotted as a function of charge, and the following interesting relationship is observed. Even though both the shorter and longer distances increase with the negative charge of the arsenates, they are weighted together as described above to give a rather constant mean As-O bond length. The same lower standard deviation for $\mathrm{HAsO}_{4}{ }^{2-}$ and $\mathrm{H}_{2} \mathrm{AsO}_{4}{ }^{-}$as previously noted in figures 4 and 5 can also be seen in Figure 7. 


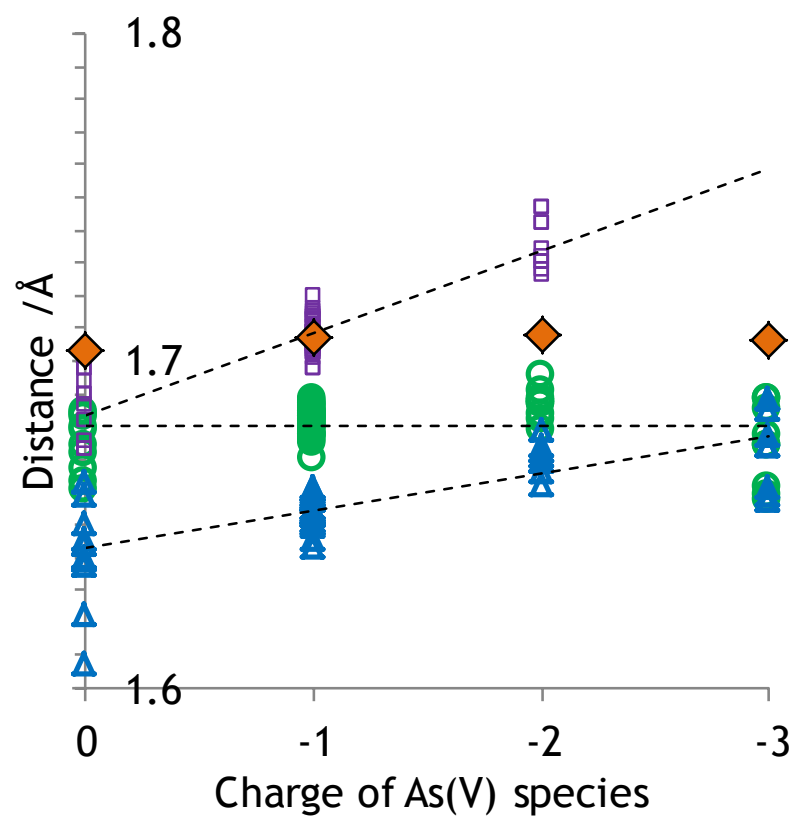

Figure 7: As-O bond distances as a function of charge on arsenic $(\mathrm{V})$ species. The shorter distance level is shown as open blue triangles, and the longer distance level as open purple squares. Mean distances are shown with open green circles. Perceived relationships are shown with dashed lines. All crystal structure data originate from crystal structure databases, refs. (61) and (62) The mean As-O bond distances from the EXAFS study in aqueous solution are included in the graph as well (orange diamonds).

A summary of the results of the crystal structure database search for species in the arsenic acid system is given in Table 2. Each of the investigated structures is presented in supporting material, Tables S1 and S3-S7. Table S2 contain a number of $\mathrm{H}_{2} \mathrm{AsO}_{4}{ }^{-}$structures in which no differentiation between long and short have been obtained. Likely reasons for this are that the model has been fitted to a space group of too high symmetry or disorder in the crystals. The mean As-O value for these sixteen structures is $1.695 \AA$ which can be compared to $1.681 \AA$ for the group of structures presented below.

Table 2: Summary of As-O distances found in crystal structures containing species from the arsenate or arsenite systems. For detailed references, see supporting material, Appendix 1.

\begin{tabular}{lrlllll}
\hline Species & No. & Short & Long & Mean & Std. dev. & References \\
\hline $\mathrm{H}_{3} \mathrm{AsO}_{4}$ & 10 & 1.641 & 1.686 & 1.674 & 0.009 & $70-78$ \\
$\mathrm{H}_{2} \mathrm{AsO}_{4}{ }^{-}$ & 38 & 1.655 & 1.708 & 1.681 & 0.004 & $76-77,79-109$ \\
$\mathrm{HAsO}_{4}{ }^{2-}$ & 10 & 1.670 & 1.736 & 1.687 & 0.005 & $110-118$ \\
$\mathrm{AsO}_{4}{ }^{3-}$ & 9 & 1.674 & & 1.674 & 0.012 & $119-126$ \\
$\mathrm{RAsO}(\mathrm{OH})_{2}$ & 17 & 1.653 & 1.705 & 1.688 & 0.007 & $127-139$ \\
$\mathrm{R}_{2} \mathrm{AsO}(\mathrm{OH})$ & 6 & 1.655 & 1.731 & 1.693 & 0.020 & $136-144$ \\
\hline
\end{tabular}


Database results for organic arsenates on the form $\mathrm{RAsO}(\mathrm{OH})_{2}$ have also been studied as shown in Figure 8. Two longer arsenic-oxygen distances and one shorter can be expected from the formula, and as in the case with inorganic arsenates, these two levels can be seen in Figure 8. The slope is intermediate between that of $\mathrm{H}_{2} \mathrm{AsO}_{4}{ }^{-}$(containing two long As-O distances) and $\mathrm{H}_{3} \mathrm{AsO}_{4}$ (containing three long As-O distances). The deviation of the short distance from the trend line is about $0.03 \AA$. The results can be compared with those of organic arsenates on the form $\mathrm{R}_{2} \mathrm{AsO}(\mathrm{OH})$, Figure 9. These structures contain only two distances whereof one is short and one is long. The long distance is substantially longer than in the case of $\mathrm{RAsO}(\mathrm{OH})_{2}$, compensating for the fact that the latter have two long distances. As a result, the mean As-O distances differ only $0.005 \AA$.

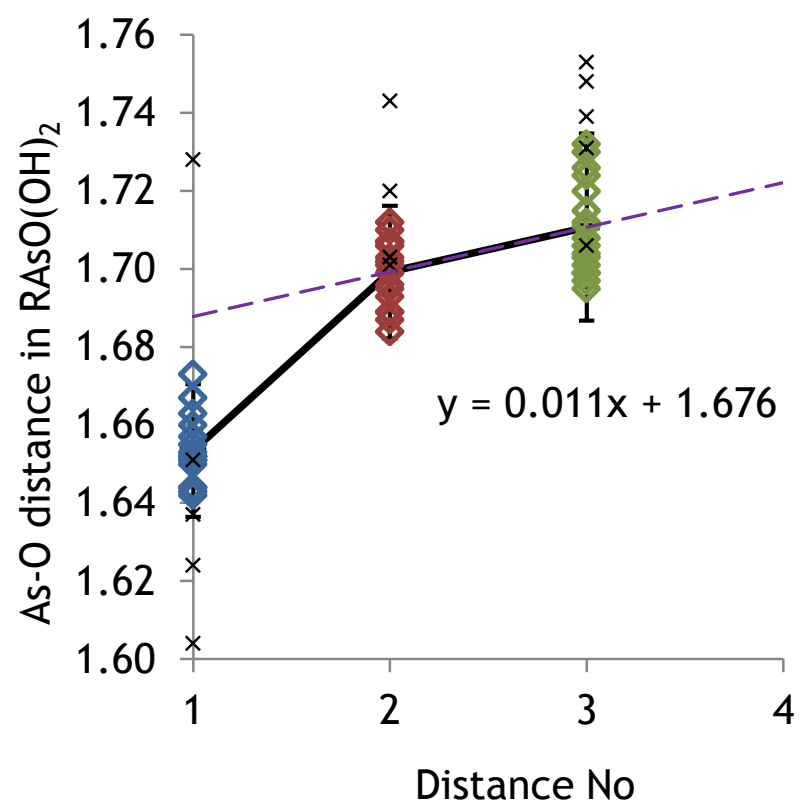

Figure 8: The three As-O distances obtained from 17 crystal structures of organic arsenates in the form $\mathrm{RAsO}(\mathrm{OH})_{2}$ Shortest distance (blue), intermediate distance (red) and longest distance (green) are shown as diamonds. From the general formula, one shorter and two longer arsenic-oxygen distances can be expected. The assumed relationship between the two longer distances is shown with a dashed line. In addition, six structures failing Grubbs statistical test for outliers are shown as crosses. All of the distances in these structures have been excluded as at least one failed the Grubbs test.

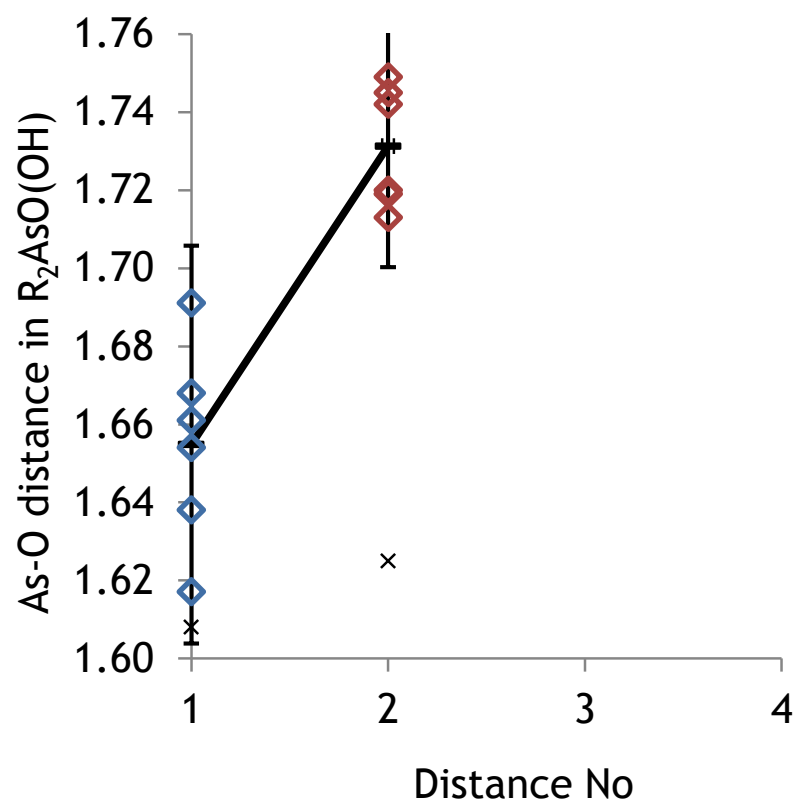

Figure 9: The two As-O distances obtained from six crystal structures of organic arsenates in the form $\mathrm{R}_{2} \mathrm{AsO}(\mathrm{OH})$. Shortest distance (blue) and longest distance (red) are shown as diamonds. From the general formula, one short and one long arsenicoxygen distances can be expected. In addition, one structure failing Grubbs statistical test for outliers is shown as crosses. Both distances in this structure have been excluded.

Regarding arsenite species, there is a lack of similar statistical material. Arsenic(III) prefers to crystallize as meta-arsenite with linear chains of $\mathrm{AsO}_{2}{ }^{-}$units, when crystallizing with low charge density cations such as the alkali metals. When arsenite does crystallize as separate $\mathrm{AsO}_{3}{ }^{-}$units, it is commonly in the presence of an ion with high charge density. This obstructs comparisons with the aqueous phase with regard to bond lengths and angles. One relevant structure, $\mathrm{Na}_{2} \mathrm{AsO}_{2} \mathrm{OH} \cdot 5 \mathrm{H}_{2} \mathrm{O}$, has As-O bond distances of $1.733,1,737$ and $1.869 \AA$, mean $1.780 \AA \AA^{145}$ This indicate a much larger difference between short and long distances, 
than in the case of arsenate structures, which could possibly be explained by the lower symmetry caused by a lone pair being repelled by charged oxygen atoms. The O-As-O angles were determined to $104.77,98.48$ and $100.25^{\circ}$, mean $=101.2^{\circ} .^{145}$ The largest value corresponds to the angle between negatively charged oxygen atoms (shorter As-O-distances). The compound $\mathrm{Na}_{5}\left(\mathrm{AsO}_{2} \mathrm{OH}\right)\left(\mathrm{AsO}_{3}\right) \cdot 12 \mathrm{H}_{2} \mathrm{O}$ was a part of the same study but unfortunately it was not possible to separate the $\mathrm{AsO}_{2} \mathrm{OH}^{2-}$ and $\mathrm{AsO}_{3}{ }^{3-}$ units from each other.

\section{XANES of hydrated arsenates and arsenites}

The XANES spectra of arsenous acid, $\mathrm{As}(\mathrm{OH})_{3}$, arsenites, $\mathrm{AsO}_{\mathrm{n}}(\mathrm{OH})_{(3-\mathrm{n})}{ }^{\mathrm{n}-}, \mathrm{n}=1$ and 3, arsenic acid, $\mathrm{H}_{3} \mathrm{AsO}_{4}$, and arsenates, $\mathrm{H}_{\mathrm{n}} \mathrm{AsO}_{4}{ }^{(3-\mathrm{n})-}, \mathrm{n}=0-2$, normalized to unit absorption at $11985 \mathrm{eV}$, are shown in Figure 10. White-line maxima are observed close to the literature value of $11871.7 \mathrm{eV}^{21}$ for all inorganic arsenic(III) species studied $\left(\mathrm{AsO}_{3}{ }^{3-}, \mathrm{AsO}_{2} \mathrm{OH}^{-}\right.$and $\left.\mathrm{As}(\mathrm{OH})_{3}\right)$. The XANES spectra of the charged arsenic(III) species are very similar with a weak shoulder at $11890 \mathrm{eV}$, which is lacking in the neutral arsenous acid. Inorganic arsenic(V) species have white-line maxima close to the literature value $11875.3 \mathrm{eV} .^{21}$ In Table 3 , individual white-line maxima are presented, and interestingly, the difference between $\operatorname{arsenic}(\mathrm{V})$ and arsenic(III) species of the same degree of protonation is $4.0 \mathrm{eV}$ in each case. Values in Table 3 are shown with two decimals in Table S8 to underline this constant difference. Analogous to the arsenic(III) species, XANES spectra of the arsenate species are very similar. A slight decrease in white-line intensity with decreasing protonation can be discerned. Also analogous to the arsenic(III) case, charged arsenate species show a more pronounced shoulder around $11890 \mathrm{eV}$. This is shown more clearly in an enlarged region of the graph, Figure S2.

The white-line maximum for the organic arsenates monomethylarsenate $(\mathrm{V}), \mathrm{MMA}=$ $\mathrm{CH}_{3} \mathrm{AsO}(\mathrm{OH})_{2}$, and dimethylarsenate $(\mathrm{V}), \mathrm{DMA}=\left(\mathrm{CH}_{3}\right)_{2} \mathrm{AsO}(\mathrm{OH})$, are observed at the slightly lower values, relative to the white line positions of inorganic arsenate species, of 11874.4 and $11874.6 \mathrm{eV}$ respectively (Figure 11). It is therefore possible from the absorption energy to distinguish between inorganic and these organic arsenic(V) species. It can be noted that the value of DMA differs from that reported by Smith et al. ${ }^{21}$ 

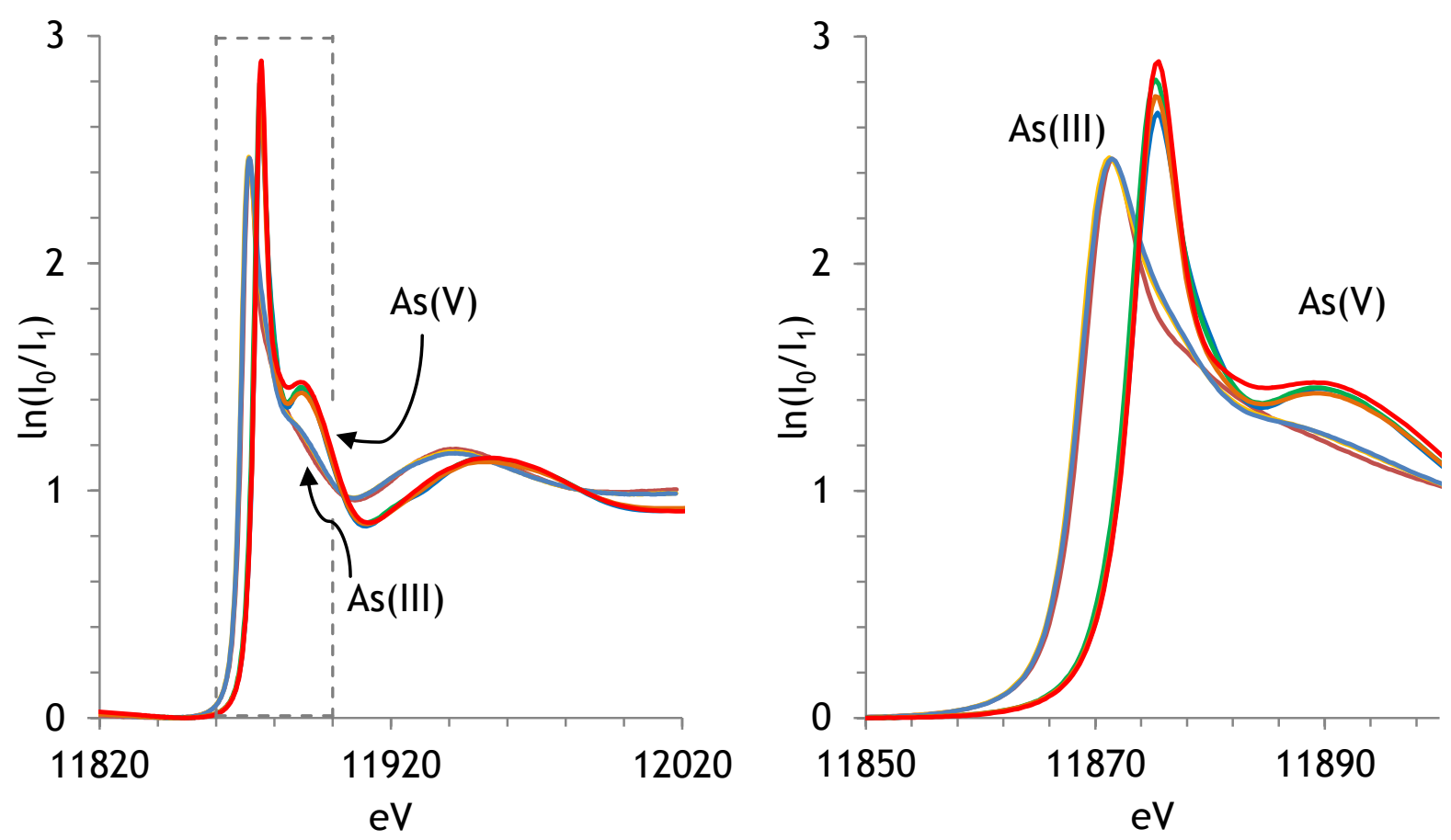

Figure 10: As $\mathrm{K}_{\alpha}$ edges of inorganic arsenic compounds. Light red: $\mathrm{As}(\mathrm{OH})_{3}$; light orange $\mathrm{AsO}(\mathrm{OH})_{2}{ }^{-}$; light blue $\mathrm{AsO}_{3}{ }^{3-}$, Red: $\mathrm{H}_{3} \mathrm{AsO}_{4}$; Orange: $\mathrm{H}_{2} \mathrm{AsO}_{4}{ }^{-}$; green $\mathrm{HAsO}_{4}{ }^{2-}$; blue $\mathrm{AsO}_{4}{ }^{3-}$. Details of the samples can be found in Table 1. Dashed lines in the left panel delimit the range shown in the right panel.

Table 3: White line maxima in $\mathrm{eV}$ for inorganic arsenic species in varied states of protonation, and for *)The literature value reported for trivalent arsenic were obtained at $\mathrm{pH} 9$, and thus speciation $\mathrm{As}(\mathrm{OH})_{3} / \mathrm{AsO}(\mathrm{OH})_{2}{ }^{-}$is unclear. MMA refers to $\mathrm{CH}_{3} \mathrm{AsO}(\mathrm{O})_{2}{ }^{2-}$ and DMA refers to $\left(\mathrm{CH}_{3}\right)_{2} \mathrm{AsO}(\mathrm{OH})$.

\begin{tabular}{|c|c|c|c|c|c|c|}
\hline Species & Peak & Literature $^{21}$ & Species & Peak & Literature $^{21}$ & Diff $A s^{V}-A s^{I I I}$ \\
\hline $\mathrm{H}_{3} \mathrm{AsO}_{4}$ & 11875.5 & & $\mathrm{As}(\mathrm{OH})_{3}$ & 11871.5 & $11871.7 *$ & 4.0 \\
\hline $\mathrm{H}_{2} \mathrm{AsO}_{4}^{-}$ & 11875.2 & 11875.3 & $\mathrm{AsO}(\mathrm{OH})_{2}^{-}$ & 11871.2 & & 4.0 \\
\hline $\mathrm{HAsO}_{4}{ }^{2-}$ & 11875.3 & & & & & \\
\hline $\mathrm{AsO}_{4}{ }^{3-}$ & 11875.4 & & $\mathrm{AsO}_{3}{ }^{3-}$ & 11871.2 & & 4.0 \\
\hline Mean As ${ }^{\mathrm{V}}$ & 11875.4 & & Mean As ${ }^{\text {III }}$ & 11871.4 & & \\
\hline MMA & 11874.4 & 11874.1 & & & & \\
\hline DMA & 11874.6 & 11873.3 & & & & \\
\hline
\end{tabular}




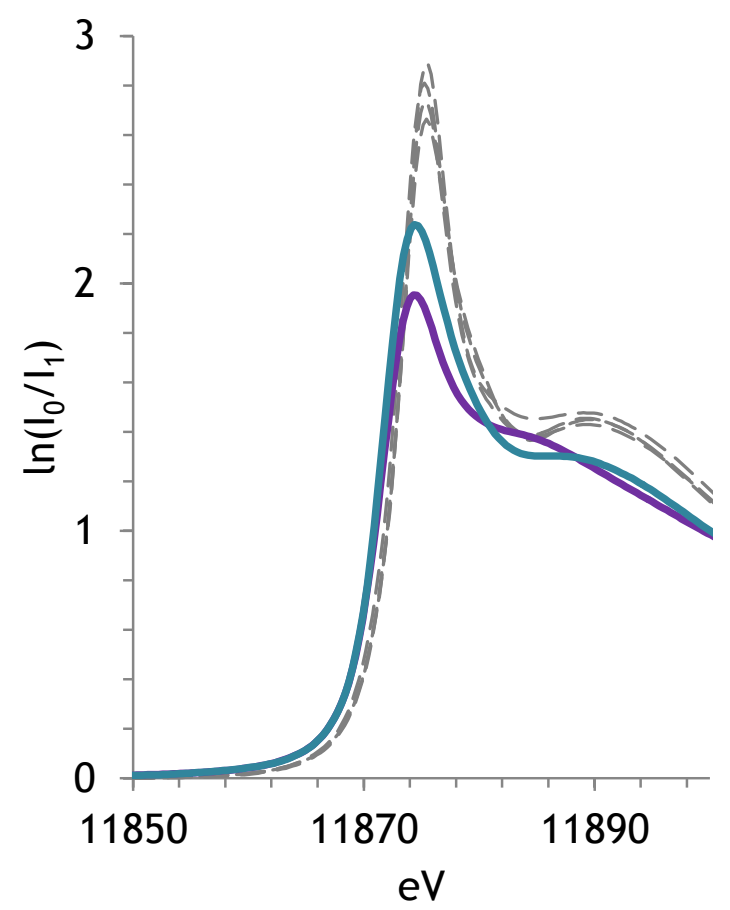

Figure 11: As $\mathrm{K}_{\alpha}$ edges of organic arsenic(V) compounds. Purple: DMA(V); turquoise MMA(V). Grey dashed lines represent inorganic arsenic(V) species.

\section{EXAFS on hydrated arsenates and arsenites}

The structures of the hydrated inorganic arsenate species have been studied by EXAFS and results are presented in Table 4 together with results from measurements of MMA and DMA. Obtained EXAFS results for the investigation of inorganic arsenites are given in Table 5, and the EXAFS functions of all inorganic species are shown in Figure S3. Obtained EXAFS results for MMA and DMA are shown in Figure S5. The similarity of the functions for species in the same oxidation state clearly shows that the mean As-O bond distance is independent of degree of protonation for both arsenate and arsenite, Figure S3, as is also found in the solid state, Figure 7. The mean As-O bond distance in the hydrated arsenates and arsenic acid, $1.706 \AA$, is 0.02-0.03 $\AA$ longer than in the solid state, Table 2, a difference also seen for other anions as perchlorate ${ }^{146}$, sulfate ${ }^{147}$ and sulfite. ${ }^{33}$ It can also be expected that the As-O bond distance distribution with significantly longer As-OH than As-O bonds is maintained in aqueous solution. This difference is however not large enough to be resolved by the methods applicable on solutions (i.e. EXAFS and LAXS). The mean As-O bond distance in the hydrated arsenites and arsenous acid, ca. $1.80 \AA$, is ca. $0.02 \AA$ longer than found for $\mathrm{AsO}_{2}(\mathrm{OH})^{2-}$ in the solid state. ${ }^{145}$ Figure 12 shows the refinements of $\mathrm{HAsO}_{4}{ }^{2-}$ and $\mathrm{As}(\mathrm{OH})_{3}$, both being representative of other species with the same oxidation state. A comparison of the above mentioned $\mathrm{As}(\mathrm{OH})_{3}$ solution with an oversaturated solution of about $0.5 \mathrm{M}$, Figure $\mathrm{S} 4$, does not show any significant differences. Hence there are no indications of polynuclear complexes such as $\mathrm{As}_{4} \mathrm{O}_{6}$ or $\mathrm{As}_{3} \mathrm{O}_{3}(\mathrm{OH})_{3},{ }^{34}$ or the concentration of such complexes are too low to affect the $\mathrm{As}(\mathrm{OH})_{3}$ EXAFS wave. 
Table 4. Mean distances, $d / \AA \AA$, number of distances, $N$, Debye-Waller coefficients, $\sigma / \AA^{2}$, threshold energy, $E_{0}$, and amplitude reduction factor, $S_{0}^{2}$, from the EXAFS studies of the hydrated arsenate(V) ions in different protonated forms and organic arsenate molecules at room temperature.

\begin{tabular}{|c|c|c|c|c|c|c|}
\hline Species & Interaction & $N$ & $d$ & $\sigma^{2}$ & $E_{\mathrm{o}}$ & $S_{\mathrm{o}}^{2}$ \\
\hline \multicolumn{7}{|l|}{ Species } \\
\hline \multirow[t]{3}{*}{$\mathrm{AsO}_{4}{ }^{3-}$} & As-O & 4 & $1.706(1)$ & $0.0013(1)$ & $11878.8(2)$ & $0.90(2)$ \\
\hline & As-O-O & 12 & $3.10(2)$ & $0.006(2)$ & & \\
\hline & $\mathrm{MS}\left(\mathrm{AsO}_{4}\right)$ & $4+12$ & $3.43(2)$ & $0.011(2)$ & & \\
\hline \multirow[t]{3}{*}{$\mathrm{HAsO}_{4}{ }^{2-}$} & As-O & 4 & $1.708(2)$ & $0.0033(2)$ & $11878.3(2)$ & $0.91(2)$ \\
\hline & As-O-O & 12 & $3.09(1)$ & $0.004(1)$ & & \\
\hline & $\mathrm{MS}\left(\mathrm{AsO}_{4}\right)$ & $4+12$ & $3.44(2)$ & $0.009(2)$ & & \\
\hline \multirow[t]{3}{*}{$\mathrm{H}_{2} \mathrm{AsO}_{4}^{-}$} & As-O & 4 & $1.707(1)$ & $0.0040(1)$ & $11878.2(2)$ & $0.90(2)$ \\
\hline & As-O-O & 12 & $3.08(1)$ & $0.004(1)$ & & \\
\hline & $\mathrm{MS}\left(\mathrm{AsO}_{4}\right)$ & $4+12$ & $3.43(3)$ & $0.009(3)$ & & \\
\hline \multirow[t]{3}{*}{$\mathrm{H}_{3} \mathrm{AsO}_{4}$} & As-O & 4 & $1.703(1)$ & $0.0032(1)$ & $11878.4(2)$ & $0.91(2)$ \\
\hline & As-O-O & 12 & $3.08(1)$ & $0.003(1)$ & & \\
\hline & $\mathrm{MS}\left(\mathrm{AsO}_{4}\right)$ & $4+12$ & $3.42(2)$ & $0.004(2)$ & & \\
\hline \multirow[t]{2}{*}{$\mathrm{CH}_{3} \mathrm{AsO}(\mathrm{OH})_{2}$} & As-O & 3 & $1.707(1)$ & $0.0050(1)$ & $11879.2(2)$ & $0.88(2)$ \\
\hline & As-C & 1 & $1.890(3)$ & $0.0012(3)$ & & \\
\hline \multirow[t]{2}{*}{$\left(\mathrm{CH}_{3}\right)_{2} \mathrm{AsO}(\mathrm{OH})$} & As-O & 2 & $1.709(1)$ & $0.0028(1)$ & $11879.3(2)$ & $0.92(2)$ \\
\hline & As-C & 2 & $1.890(2)$ & $0.0013(2)$ & & \\
\hline
\end{tabular}


Table 5. Threshold energy, $E_{\mathrm{o}}$, and amplitude reduction factor, $S_{\mathrm{o}}{ }^{2}$, distances, $d / \AA$, number of distances, $N$, Debye-Waller coefficients, $\sigma / \AA^{2}$, from the EXAFS studies of hydrated arsenous acid and arsenite ions at room temperature.

\begin{tabular}{llllllll}
\hline Species & Interaction & $N$ & $d$ & $\sigma^{2}$ & $E_{\mathrm{o}}$ & $S_{\mathrm{o}}{ }^{2}$
\end{tabular}

\begin{tabular}{llrllll}
\hline $\begin{array}{l}\text { Species } \\
\mathrm{AsO}_{4}{ }^{3-}\end{array}$ & $\mathrm{As}-\mathrm{O}$ & 3 & $1.798(1)$ & $0.0042(1)$ & $11876.5(2)$ & $0.91(2)$ \\
& $\mathrm{MS}\left(\mathrm{AsO}_{3}\right)$ & $2 \times 3$ & $3.595(11)$ & $0.0085(10)$ & & \\
& & & & & & \\
$\mathrm{AsO}(\mathrm{OH})_{2}^{-}$ & $\mathrm{As}-\mathrm{O}$ & 3 & $1.801(3)$ & $0.0035(4)$ & $11878.6(2)$ & $0.90(2)$ \\
& $\mathrm{MS}\left(\mathrm{AsO}_{3}\right)$ & $2 \times 3$ & $3.60(2)$ & $0.007(2)$ & & \\
& & & & & & \\
$\mathrm{As}(\mathrm{OH})_{3}$ & $\mathrm{As}^{-}$ & 3 & $1.802(1)$ & $0.0028(1)$ & $11876.8(2)$ & $0.90(2)$ \\
& $\mathrm{MS}\left(\mathrm{AsO}_{3}\right)$ & $2 \times 3$ & $3.605(8)$ & $0.0059(8)$ & &
\end{tabular}

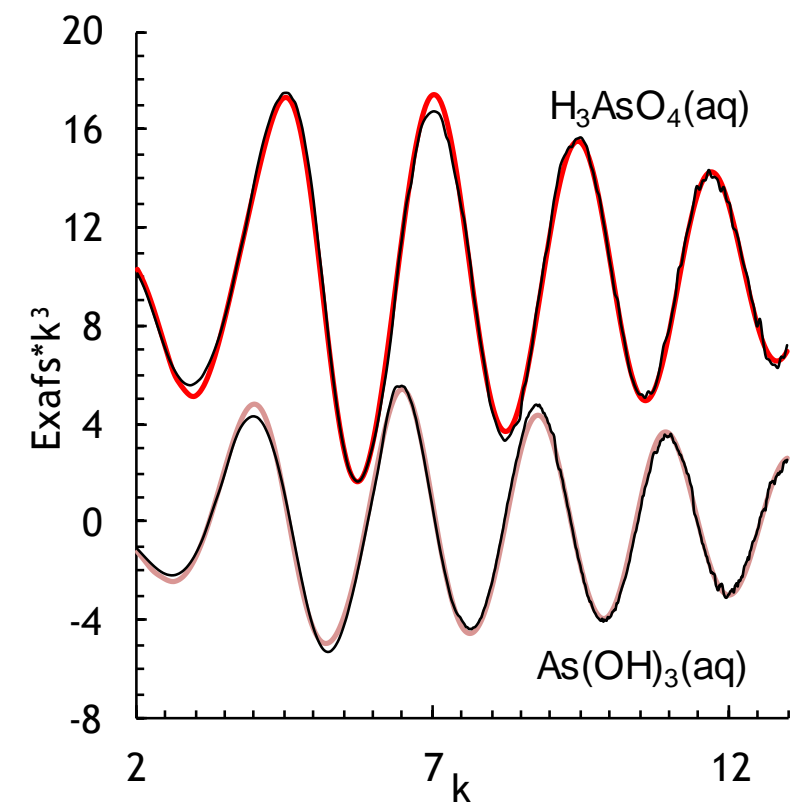

Figure 12: Experimental (black lines) and calculated EXAFS data for arsenic acid, $\mathrm{H}_{3} \mathrm{AsO}_{4}$ (red line) and arsenous acid, $\mathrm{As}(\mathrm{OH})_{3}$, (purple line).

\section{Large Angle X-ray Scattering}

$\mathrm{A} \mathrm{Na}_{2} \mathrm{HAsO}_{4}$ solution of $\mathrm{pH} 12.8$, a $\mathrm{NaAsO}_{2}$ solution at $\mathrm{pH} 10.6$ and a $\mathrm{Te}(\mathrm{OH})_{6}$ solution was investigated by large angle $\mathrm{X}$-ray scattering, and a summary of fitted parameters can be found in Table 6 . Recurring distances in aqueous solution as well as temperature 
coefficients are shown for the hydrated species $\mathrm{AsO}_{4}{ }^{3-}, \mathrm{AsO}(\mathrm{OH})_{2}{ }^{-}$and $\mathrm{Te}(\mathrm{OH})_{6}(\mathrm{aq})$, as well as for solvent-solvent interactions and interactions with counter ions.

Table 6: Mean distances, $d / \AA$, number of distances, $N$, temperature coefficients, $b / \AA^{2}$, and the half-height full width, $l / \AA$, in the LAXS studies of hydrated arsenic oxyanions in aqueous solution at room temperature.

\begin{tabular}{lllllc}
\hline Species & Interaction & $N$ & $d$ & $b$ & $l$ \\
\hline AsO $_{4}{ }^{3-}$ in water, $1.5006 ~ m o l \cdot d m^{-3}$ & & & & \\
$\mathrm{AsO}_{4}{ }^{3-} / \mathrm{aq}$ & $\mathrm{As}-\mathrm{O}$ & 4 & $1.704(3)$ & $0.0020(2)$ & $0.063(3)$ \\
& $\mathrm{As}(\mathrm{OH}) \cdots \mathrm{O}$ & 8 & $3.929(5)$ & $0.0212(7)$ & $0.206(4)$ \\
& $(\mathrm{As}) \mathrm{O}-(\mathrm{H}) \cdots \mathrm{O}$ & 8 & $2.783(9)$ & $0.0134(11)$ & $0.164(7)$ \\
& $\mathrm{Na}-\mathrm{O}$ & 6 & $2.429(8)$ & $0.0234(6)$ & $0.216(2)$ \\
$\mathrm{Na}\left(\mathrm{OH}_{2}\right)_{6}{ }^{+}$ & $\mathrm{O} \cdots \mathrm{O}$ & 2 & $2.888(4)$ & $0.0193(5)$ & $0.196(3)$ \\
Water bulk & & & &
\end{tabular}

$\mathrm{AsO}(\mathrm{OH})_{2}{ }^{-}$in water, $1.5041 \mathrm{~mol} \cdot \mathrm{dm}^{-3}$

$\begin{array}{llrlll}\mathrm{As}(\mathrm{OH})_{2} \mathrm{O}^{-} / \mathrm{aq} & \mathrm{As}-\mathrm{O} & 3 & 1.785(2) & 0.0023(2) & 0.068(3) \\ & \mathrm{As}(\mathrm{OH}) \cdots \mathrm{O} & 9 & 4.096(4) & 0.0245(6) & 0.221(3) \\ & (\mathrm{As}) \mathrm{O}-(\mathrm{H}) \cdots \mathrm{O} & 9 & 2.865(11) & 0.016(3) & 0.18(2) \\ \mathrm{Na}\left(\mathrm{OH}_{2}\right)_{6}{ }^{+} & \mathrm{Na}-\mathrm{O} & 6 & 2.436(12) & 0.022(1) & 0.21(1) \\ \text { Water bulk } & \mathrm{O} \cdots \mathrm{O} & 2 & 2.889(4) & 0.0203(5) & 0.201(3)\end{array}$

$\mathrm{Te}(\mathrm{OH})_{6}$ in water, $2.0003 \mathrm{~mol} \cdot \mathrm{dm}^{-3}$

$\begin{array}{llrllr}\mathrm{Te}(\mathrm{OH})_{6} / \mathrm{aq} & \mathrm{Te}-\mathrm{OH} & 6 & 1.940(2) & 0.0012(1) & 0.049(2) \\ & \mathrm{Te}(\mathrm{OH}) \cdots \mathrm{O} & 12 & 4.140 & 0.01947 & 0.1973 \\ & (\mathrm{Te}) \mathrm{O}-(\mathrm{H}) \cdots \mathrm{O} 12 & 2.845 & 0.044(3) & 0.1646\end{array}$

$\begin{array}{llllll}\text { Water bulk } & \mathrm{O} \cdots \mathrm{O} & 2 & 2.888(7) & 0.0203(13) & 0.201(3)\end{array}$

Dihydrogen arsenite and arsenate ions in water

The structures of the hydrated $\mathrm{AsO}_{4}{ }^{3-}$ and $\mathrm{AsO}(\mathrm{OH})_{2}{ }^{-}$ions in aqueous solution have been determined by large angle X-ray scattering (LAXS). The radial distribution function (RDF) for the arsenate ion the aqueous solution ( $\mathrm{pH}$ 12.8) show three peaks at 1.7, 2.9 and 3.9 $\AA$, which corresponds to the mean As-O bond distance, the mean $\mathrm{O} \cdots \mathrm{O}$ in the aqueous bulk and the distance between arsenic and the hydrating water oxygens, As- $(\mathrm{O}) \cdots \mathrm{O}$, respectively, and a very weak shoulder at $2.4 \AA$ corresponding the hydrated sodium ion, Figure 13 . The mean As-O bond distance was refined to 1.704(9) $\AA$, and the As- $(\mathrm{O}) \cdots \mathrm{O}$ distance to 3.929(13) $\AA$, the (As-) $\mathrm{O} \cdots \mathrm{O}$ distance to 2.78(2) which corresponds to an As-O-O bond angle of $120.3^{\circ}$. The short (As-) $\mathrm{O} \cdots \mathrm{O}$ distance shows that the arsenate ion indeed is a structure maker similar to the sulfate and phosphate ions. ${ }^{147,148}$ The As-O-O bond angle strongly 
indicates that two water molecules strongly hydrogen bind to each arsenate oxygen. The $\mathrm{O} \cdots \mathrm{O}$ distance in the aqueous bulk was refined to $2.89(2)$, which is the normal value for this distance in aqueous electrolyte solutions. The $\mathrm{Na}-\mathrm{O}$ bond distance in the hydrated sodium ion, refined to 2.43(2) $\AA$, is in full agreement with previous studies. ${ }^{69}$

The radial distribution function (RDF) for the aqueous solution of sodium metaarsenite (pH 10.6) show three peaks at 1.8, 2.9 and 4.1 $\AA$, which corresponds to the mean As-O bond distance, the mean $\mathrm{O} \cdots \mathrm{O}$ in the aqueous bulk and the distance between arsenic and the hydrating water oxygens, As- $(\mathrm{O}) \cdots \mathrm{O}$, respectively, and a very weak shoulder at $2.4 \AA$ corresponding the hydrated sodium ion, Figure 14. The mean As-O bond distance was refined to $1.785(5) \AA$, and the As- $(\mathrm{O}) \cdots \mathrm{O}$ distance to 4.096(10) $\AA$, the (As-) $\mathrm{O} \cdots \mathrm{O}$ distance to 2.86(3) $\AA$ which corresponds to an As-O-O bond angle of $122^{\circ}$. The (As-)O $\cdots \mathrm{O}$ distance shows that the dihydrogen arsenite ion is a weak structure and the As-O-O bond angle indicates that in principle two water molecules hydrogen bind to each arsenite oxygen. The $\mathrm{O} \cdots \mathrm{O}$ distance in the aqueous bulk was refined to $2.889(10) \AA$. The As-O bond distances obtained by LAXS are in excellent agreement with the results from the EXAFS study presented above.
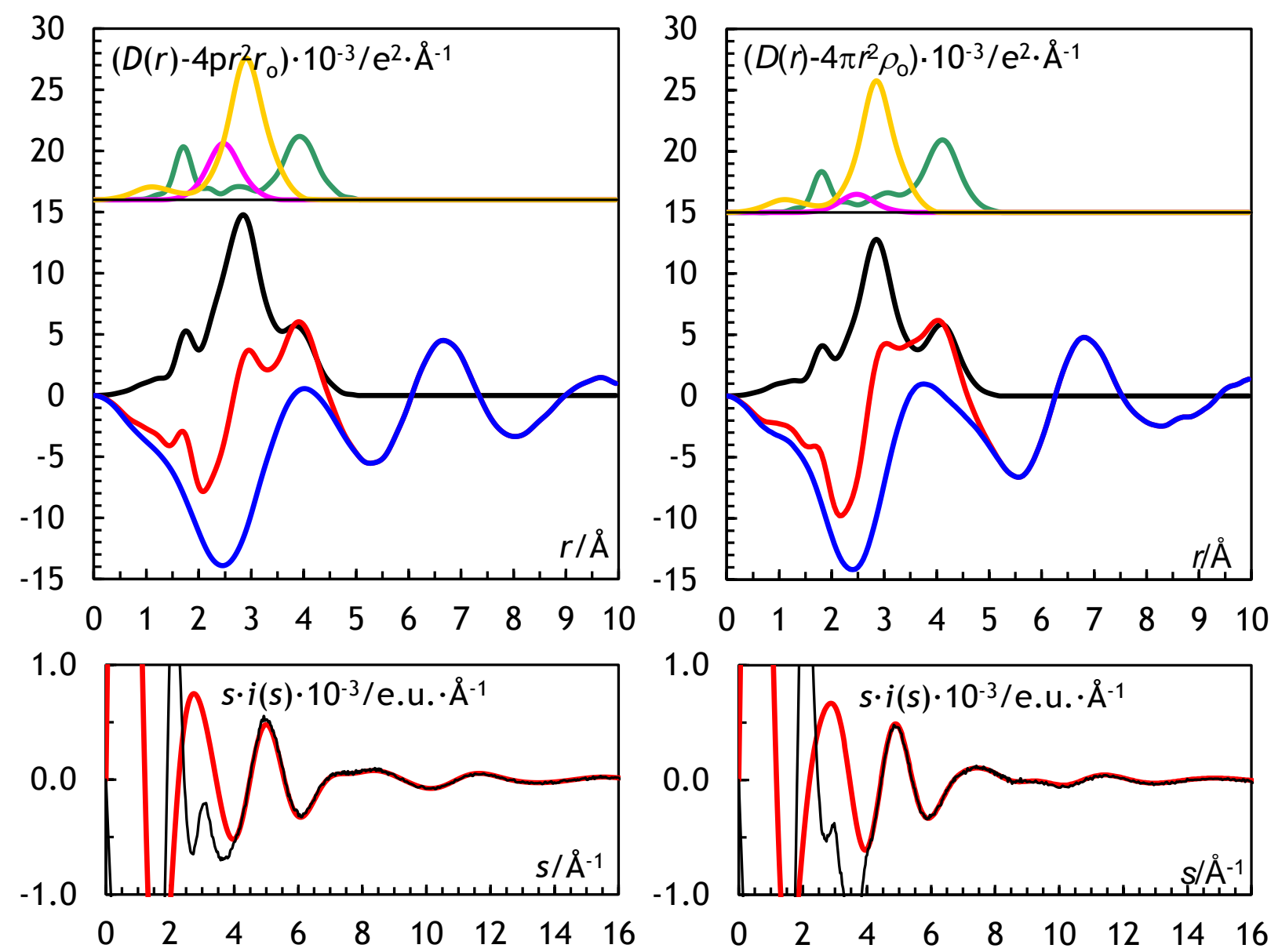

Figure 13: (Top) LAXS radial distribution curves for a $1.501 \mathrm{~mol} \cdot \mathrm{dm}^{-3}$ aqueous solution of $\mathrm{AsO}_{4}{ }^{2-}$. Upper part: Separate model contributions (offset: 16) of internal As-O distances (green line), the hydrated sodium ion (pink line) and the aqueous bulk (orange line). (Middle) Experimental RDF: $D(r)-4 \pi r^{2} \rho_{\mathrm{o}}$ (red line), sum of model contributions (black line) and the

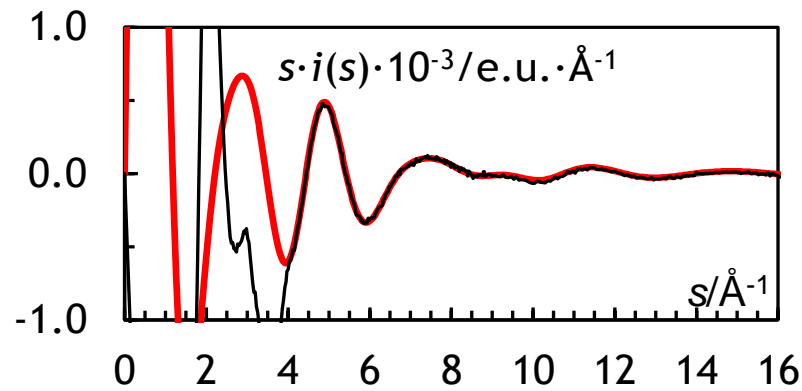

Figure 14: (Top) LAXS radial distribution curves for a $1.504 \mathrm{~mol} \cdot \mathrm{dm}^{-3}$ aqueous solution of $\mathrm{AsO}(\mathrm{OH})_{2}{ }^{-}$. Upper part: Separate model contributions (offset: 15) of internal As-O distances (green line), the hydrated sodium ion (pink line) and the aqueous bulk (light orange line). (Middle) Experimental RDF: $D(r)-4 \pi r^{2} \rho_{\mathrm{o}}$ (red line), sum of model contributions (black line) and 
difference between experimental and calculated functions (blue line). (Bottom) Reduced LAXS intensity functions $\mathrm{s} \cdot \mathrm{i}(\mathrm{s})$ (black line); model $\mathrm{s} \cdot \mathrm{i}_{\text {calc }}(\mathrm{s})$ (red line). the difference between experimental and calculated functions (blue line). (Bottom) Reduced LAXS intensity functions $\mathrm{s} \cdot \mathrm{i}(\mathrm{s})$ (solid line); model $\mathrm{s} \cdot \mathrm{i}_{\text {calc }}(\mathrm{s})$ (red line).

\section{Orthotelluric acid}

Modeling $\mathrm{Te}(\mathrm{OH})_{6}$ is especially advantageous, as no counter ion is needed and orthotelluric acid is the only species in solution except for the solvent that exists at high concentration. At the same time, $\mathrm{As}(\mathrm{OH})_{3}$ is not soluble enough to fulfill the requirements of LAXS measurements, and orthotelluric acid may serve a model for the hydration of arsenous acid. In the case of orthotelluric acid, distances originating from well-defined peaks such as the Te-OH intramolecular distances and the distance between tellurium and hydrating water oxygen can be considered very accurate, Figure S6. The octahedral structure of $\mathrm{Te}(\mathrm{OH})_{6}$ is confirmed in this work and the Te-OH distance of 1.940(4) $\AA$ is in the same range as in previous work. ${ }^{39}$ This means that the Te-OH distance in aqueous solutions is about $0.025 \AA$ longer than in crystal structures ${ }^{38-46}$, which is in agreement with hydrated anions such as perchlorate $^{146}$, sulfate $^{147}$ and sulfite ${ }^{33}$, as well as for arsenate. The Te-(OH) $\cdots \mathrm{O}$ distance, refined to $4.140 \AA$, together with the Te-O bond distance, $1.940(6) \AA$, the Te- $(\mathrm{OH}) \cdots \mathrm{O}$ distance, refined to $2.845 \AA$, give a Te-O $(\mathrm{H}) \cdots \mathrm{O}$ bond angle of $118.6^{\circ}$. This indicates that approximately two water molecules are bound to each hydroxyl group, Figure 15.

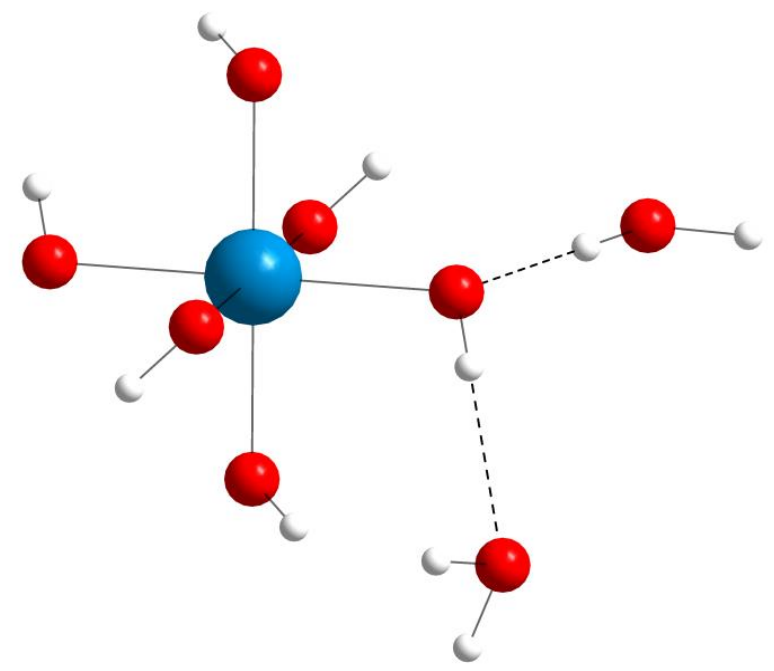

Figure 15: Hydration of orthotelluric acid with two water molecules at each hydroxyl group. The hydration possibilities are either $\mathrm{HOH}$ interacting with the oxygen side of the hydroxyl group or $\mathrm{OH}_{2}$ with the hydrogen side

\section{Double Difference Infrared Spectroscopy}

As in the case of LAXS, it is beneficial to model $\mathrm{Te}(\mathrm{OH})_{6}$ since there is no counter ion. As described in the experimental section, an affected spectrum represents solvent molecules in the vicinity of an ion or molecule. The affected spectrum of hydrated $\mathrm{Te}(\mathrm{OH})_{6}$ in aqueous 
solution is shown in Figure 16, and contain one Gaussian peak at $2340 \mathrm{~cm}^{-1}$, and one peak at $2533 \mathrm{~cm}^{-1}$ which can be described as a combination of two Gaussian sub-peaks. The weighted center of the latter peak occurs at $2513 \mathrm{~cm}^{-1}$ and the weighted center of the entire affected spectrum occurs at $2449 \mathrm{~cm}^{-1}$. The affected number $N$ was found to be 9.7 .

Considering the affected spectrum in Figure 16, it can be seen that it is skewed towards lower wave numbers, indicating a possible weak structure making effect. In the model applied, three individual Gaussian peaks make up the affected spectrum of $\mathrm{Te}(\mathrm{OH})_{6}(\mathrm{aq})$. The most interesting peak is the one at $2340 \mathrm{~cm}^{-1}$, as it is responsible for the skewed shape of the affected spectrum. We would like to propose that this peak is mainly due to interactions with the hydroxyl hydrogen, Figure 15 . The acidity of the $(\mathrm{HO})_{5} \mathrm{TeO}-\mathrm{H}$ bond should cause an increased charge separation compared to the much less acidic water molecule. Due to this increased charge separation, partial charge density increases relatively more for the light hydroxyl hydrogen than for the hydroxyl oxygen, giving the smaller atom the property of a weak structure maker in aqueous solution. The peaks at 2564 and $2474 \mathrm{~cm}^{-1}$ should originate from HDO molecules interacting with the hydroxyl oxygen, but it is unclear whether both have physical significance or if they should be treated as one peak with asymmetric distribution. Due to the almost Gaussian shape of the combined peak at $2533 \mathrm{~cm}^{-1}$, sub-peaks are not further assigned to particular interactions here. A more speculative alternative interpretation is included in supplementary material, Appendix 4.

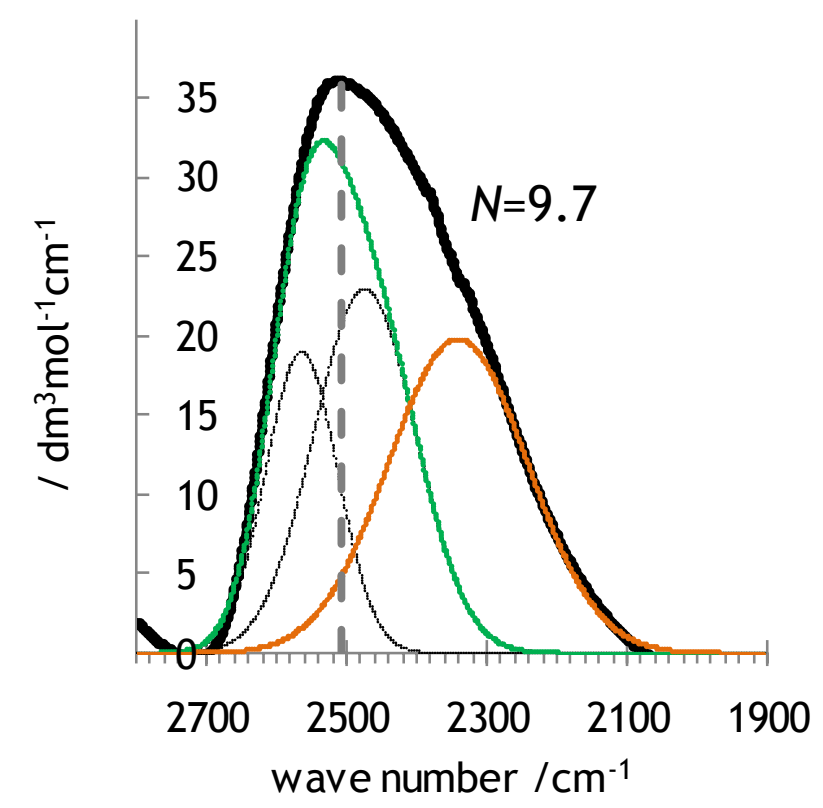

Figure 16: Affected spectrum of $\mathrm{Te}(\mathrm{OH})_{6}(\mathrm{aq})$. The spectrum is modeled from 3 individual contributions of Gaussian character. The green line is the Gaussian combination of peaks at $2564 \mathrm{~cm}^{-1}$ and $2474 \mathrm{~cm}^{-1}$ while the orange line is a Gaussian peak at $2340 \mathrm{~cm}^{-1}$. The position of bulk water at $2509 \mathrm{~cm}^{-1}$ is shown as a grey dashed line.

Arsenous acid is much less water soluble than orthotelluric acid, and $\mathrm{As}_{2} \mathrm{O}_{3}$ may precipitate at concentrations around $0.2 \mathrm{~mol} \cdot \mathrm{dm}^{-3} \cdot{ }^{10,11}$ The lower solubility of $\mathrm{As}(\mathrm{OH})_{3}$ causes the double difference spectrum to be noisy and less certain, Figure S8, but the general features are in line with that of orthotelluric acid, Figure 16. The shape of the affected spectrum can be 
modeled with two Gaussian peaks located at 2511 and $2331 \mathrm{~cm}^{-1}$ respectively. The affected number $N=15.2$ found for $\mathrm{As}(\mathrm{OH})_{3}$ with the standard procedure is presumably wrong, as an effect of the noisy derivative for the low concentrations investigated, Figure 17. As can be seen from equation 1 , the impact of a noisy concentration derivative increase with decreasing affected number $N$. However, an alternative evaluation with $N=6$ give the same result with respect to peak positions $\left( \pm 3 \mathrm{~cm}^{-1}\right)$, Figure $\mathrm{S} 8$.

Analogous to $\mathrm{Te}(\mathrm{OH})_{6}$, we propose that $\mathrm{As}(\mathrm{OH})_{3}$ is a weak structure maker as a significant contribution is found at lower wave numbers. This shifts the spectrum weighted average to wave numbers lower than that of bulk water, Figure S8. The similarity between $\mathrm{Te}(\mathrm{OH})_{6}$ and $\mathrm{As}(\mathrm{OH})_{3}$ is perhaps more convincingly shown by comparing derivatives with respect to concentration, Figure 17. These derivatives are calculated from raw data, without dependence on chosen affected number. For the same reason as with orthotelluric acid, the structure making properties of arsenous acid should originate from HDO interactions with the acidic hydroxyl hydrogen.

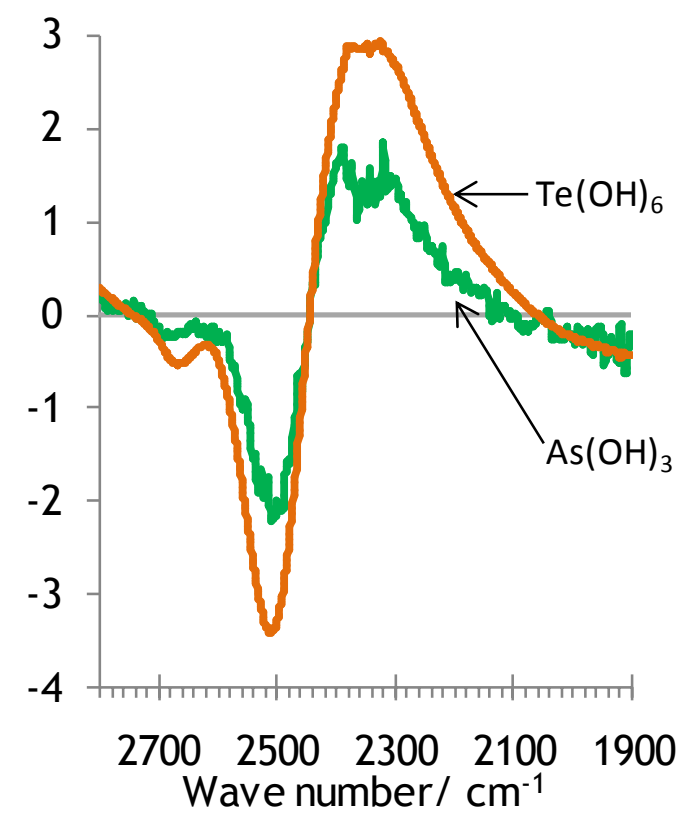

Figure 17: Derivatives with respect to concentration for orthotelluric acid and arsenous acid.

\section{Conclusions}

It can be established that average As-O distances in arsenate-containing crystals are very similar despite large differences in individual distances due to protonation. The system of distances as a whole appears to compensate deviating distances to obtain a fairly constant average. EXAFS measurements of the species in the $\mathrm{H}_{3} \mathrm{AsO}_{4}$ system in aqueous solution confirm the picture with a mean As-O bond distance independent of degree of protonation. As-O distances in inorganic arsenic(III) species are about $0.1 \AA$ longer than in arsenic(V) species as determined by EXAFS.

As-O distances in aqueous solution were found to be about $0.02 \AA$ longer than in the crystal structure investigation, which is in the same range as previously found for other anions such as perchlorate ${ }^{146}$, sulfate ${ }^{147}$ and sulfite. ${ }^{33}$ A similar relationship was also confirmed for the Te-O distance in orthotelluric acid. 
The conformity of shape and positions of XANES edges between inorganic species with the same oxidation state is good but even more striking is the relationship between arsenic(III) and arsenic(V) species of the same degree of protonation, each differing by 4.00-4.01 eV. $\mathrm{H}_{3} \mathrm{AsO}_{4}$ and $\mathrm{As}(\mathrm{OH})_{3}$, as the only neutral inorganic species investigated, differ slightly from other species with the respective oxidation state, as shown by somewhat smoother spectra with less pronounced features. The organic species MMA and DMA can be distinguished from inorganic arsenic(V) species by their slightly lower white-line maxima values (about 1 $\mathrm{eV}$ ) and lower intensities.

Double Difference Infrared Spectroscopy indicate that the hydration of both orthotelluric acid, $\mathrm{Te}(\mathrm{OH})_{6}$, and arsenous acid, $\mathrm{As}(\mathrm{OH})_{3}$, is sufficiently strong to strengthen the hydrogen bonded network of water. They should therefore be classified as weak structure makers.

\section{Acknowledgements}

The Swedish International Development cooperation Agency (SIDA) and the Swedish Research Council (VR) are greatly acknowledged for funding research in this project. Portions of the research were carried out at beam-line I811, MAX-lab synchrotron radiation source, Lund University, Sweden. Funding for the beam-line I811 project was kindly provided by the Swedish Research Council and the "Knut och Alice Wallenbergs Stiftelse".

\section{References}

1. P. Smedley and D. Kinniburgh, Appl. Geochem., 2002, 17, 517-568.

2. M. Magalhaes, Pure Appl. Chem., 2002, 74, 1843-1850.

3. S. Acharyya, P. Chakraborty, S. Lahiri, B. Raymahashay, S. Guha, and A. Bhowmik, Nature, 1999, 401, 545-545.

4. N. N. Greenwood and A. Earnshaw, in Chemistry of the Elements, Butterworth Heinemann, 2nd edn., 1997, pp. 547-599.

5. L. Charlet, S. Chakraborty, C. A. J. Appelo, G. Roman-Ross, B. Nath, A. A. Ansari, M. Lanson, D. Chatterjee, and S. B. Mallik, Appl. Geochem., 2007, 22, 1273-1292.

6. O. Ni Dhubhghaill and P. Sadler, Struct. Bond., 1991, 78, 129-190.

7. J. Raposo, J. Sanz, O. Zuloaga, M. Olazabal, and J. Madariaga, Talanta, 2002, 57, 849-857.

8. S. W. Park, C. W. Kim, J. H. Lee, G. Shim, and K. S. Kim, J. Phys. Chem. A, 2011, 115, 11355-11361.

9. $p H$ in Drinking-water. Background document for development of WHO Guidelines for Drinking-water Quality, WHO, 2003.

10. I. Puigdomenech, Hydrochemical Equilibrium-Constant Database, 2004.

11. I. Puigdomenech, Medusa, 2009.

12. S. Myneni, S. Traina, G. Waychunas, and T. Logan, Geochim. Cosmochim. Acta, 1998, 62, 3285-3300.

13. B. Manning, S. Fendorf, B. Bostick, and D. Suarez, Environ. Sci. Technol., 2002, 36, 976981.

14. J. S. Loring, M. H. Sandström, K. Noren, and P. Persson, Chem.-Eur. J., 2009, 15, 50635072.

15. M. Farquhar, J. Charnock, F. Livens, and D. Vaughan, Environ. Sci. Technol., 2002, 36, 1757-1762.

16. S. O'Reilly, D. Strawn, and D. Sparks, Soil Sci. Soc. Am. J., 2001, 65, 67-77. 
17. B. Manning, S. Fendorf, and S. Goldberg, Environ. Sci. Technol., 1998, 32, 2383-2388.

18. S. Fendorf, M. Eick, P. Grossl, and D. Sparks, Environ. Sci. Technol., 1997, 31, 315-320.

19. S. Chakraborty, F. Bardelli, M. Mullet, J.-M. Greneche, S. Varma, J.-J. Ehrhardt, D. Banerjee, and L. charlet, Chem. Geol., 2011, 281, 83-92.

20. G. Waychunas, B. Rea, C. Fuller, and J. Davis, Geochim. Cosmochim. Acta, 1993, 57, 22512269.

21. P. G. Smith, I. Koch, R. A. Gordon, D. F. Mandoli, B. D. Chapman, and K. J. Reimer, Environ. Sci. Technol., 2005, 39, 248-254.

22. B. C. Bostick and S. Fendorf, Geochim. Cosmochim. Acta, 2003, 67, 909-921.

23. B. C. Bostick, S. Fendorf, and B. A. Manning, Geochim. Cosmochim. Acta, 2003, 67, 895907.

24. B. Manning, M. Hunt, C. Amrhein, and J. Yarmoff, Environ. Sci. Technol., 2002, 36, 54555461.

25. A. Bhattacharjee, A. B. Pribil, L. H. V. Lim, T. S. Hofer, B. R. Randolf, and B. M. Rode, J. Phys. Chem. B, 2010, 114, 3921-3926.

26. R. Bowell, Appl. Geochem., 1994, 9, 279-286.

27. R. X. Chen, B. W. Smith, J. D. Winefordner, M. S. Tu, G. Kertulis, and L. Q. Ma, Anal. Chim. Acta, 2004, 504, 199-207.

28. T. Loehr and R. Plane, Inorg. Chem., 1968, 7, 1708-1714.

29. V. Zakaznova-Herzog, T. Seward, and O. Suleimenov, Geochim. Cosmochim. Acta, 2006, 70, $1928-1938$.

30. N. Konopik and O. Leberl, Mon. Chem., 1949, 80, 655-669.

31. D. Testemale, J. Hazemann, G. Pokrovski, Y. Joly, J. Roux, R. Argoud, and O. Geaymond, J. Chem. Phys., 2004, 121, 8973-8982.

32. J. Hernandez-Cobos, M. C. Vargas, A. Ramirez-Solis, and I. Ortega-Blake, J. Chem. Phys., 2010, 133, 114501-1 -114501-9.

33. L. Eklund, T. S. Hofer, A. B. Pribil, B. M. Rode, and I. Persson, Dalton Trans., 2012, 41, 5209-5216.

34. J. Tossell, Geochim. Cosmochim. Acta, 1997, 61, 1613-1623.

35. H. Ellison, E. Healy, and J. Edwards, J. Am. Chem. Soc., 1962, 84, 1820-1824.

36. N. N. Greenwood and A. Earnshaw, in Chemistry of the Elements, Butterworth Heinemann, 2nd edn., 1997.

37. R. C. Weast, Handbook of Chemistry and Physics, CRC Press, 56th edn., 1975.

38. D. Qui, B. Lambertandron, and J. Boucherle, Acta Crystallogr., Sect. C, 1987, 43, 907-909.

39. D. Qui, J. Vicat, and A. Durif, Acta Crystallogr., Sect. C, 1984, 40, 181-184.

40. M. Driess, K. Merz, and R. Rowlings, Z. Anorg. Allg. Chem., 2001, 627, 213-217.

41. M. AverbuchPouchot and A. Durif, Acta Crystallogr., Sect. C, 1990, 46, 2236-2238.

42. M. Ilczyszyn, T. Lis, J. Baran, and H. Ratajczak, J. Mol. Struct., 1992, 265, 293-310.

43. M. AverbuchPouchot and U. Schulke, Z. Anorg. Allg. Chem., 1996, 622, 1997-2002.

44. M. AverbuchPouchot and A. Durif, Comptes Rendus De L Academie Des Sciences Serie Ii, 1989, 309, 25-28.

45. M. AverbuchPouchot, Z. Kristall., 1988, 183, 285-291.

46. I. Cisarova, J. Podlahova, and J. Podlaha, Collect. Czech. Chem. Commun., 1995, 60, 820828.

47. W. Levason, R. D. Oldroyd, and M. Webster, J. Chem. Soc., Dalton Trans., 1994, 29832988.

48. E. Andersson, O. Lindqvist, and T. Yamaguchi, Acta Chem. Scand. Ser. A, 1981, 35, 591597.

49. W. Dutton and W. Cooper, Chem. Rev., 1966, 66, 657-675. 
50. A. Thompson, D. Attwood, E. Gullikson, M. Howells, K.-J. Kim, J. Kirz, J. Kortright, I. Lindau, Y. Liu, P. Pianetta, A. Robinson, J. Scofield, J. Underwood, G. Williams, and H. Winick, X-ray data booklet, Lawrence Berkley National Laboratory, 2009.

51. G. N. George and I. J. Pickering, EXAFSPAK - A suite of Comuter Programs for Analysis of $X$-ray absorption spectra, SSRL, Stanford CA, 2003.

52. A. Filipponi and A. DiCicco, Phys. Rev. B, 1995, 52, 15135-15149.

53. S. Zabinsky, J. Rehr, A. Ankudinov, R. Albers, and M. Eller, Phys. Rev. B, 1995, 52, 29953009.

54. C. Stålhandske, I. Persson, M. Sandström, and E. Kamienska-Piotrowicz, Inorg. Chem., 1997, 36, 3174-3182.

55. G. Johansson and M. Sandström, Chem. Scr., 1973, 4, 195-198.

56. M. Molund and I. Persson, Chem. Scr., 1985, 25, 197-197.

57. A. Wilson, International Tables for Crystallography, Kluwer Academic Publishers, Dordrecht, The Netherlands, 1995, vol. C.

58. D. Cromer, J. Chem. Phys., 1969, 50, 4857-4859.

59. D. Cromer and J. Mann, J. Chem. Phys., 1967, 47, 1892-1894.

60. H. Levy, M. Danford, and A. Narten, Data Collection and Evaluation with an X-ray Diffractometer Designed for the Study of Liquid Structure, Oak Ridge National Laboratory, Oak Ridge, 1966.

61. F. H. Allen, Acta Crystallogr. Sect. B-Struct. Commun., 2002, 58, 380-388.

62. Inorganic Crystal Structure Database, FIZ, Karlsruhe, 2009.

63. F. Grubbs, Technometrics, 1969, 11, 1-21.

64. W. Stefansky, Technometrics, 1972, 14, 469-479.

65. A. Eriksson, O. Kristiansson, and J. Lindgren, J. Mol. Struct., 1984, 114, 455-458.

66. J. Stangret, Spectr. Lett., 1988, 21, 369-381.

67. J. Stangret and T. Gampe, J. Phys. Chem. B, 1999, 103, 3778-3783.

68. I. Persson, AIP Conf. Proc., 2007, 963, 614-620.

69. J. Mähler and I. Persson, Inorg. Chem., 2012, 51, 425-438.

70. H. Worzala, Acta Crystallogr., Sect. B, 1968, B 24, 987-991.

71. M. Amri, N. Zouari, T. Mhiri, and P. Gravereau, J. Alloy. Compd., 2009, 477, 68-75.

72. W. Schildkamp, G. Schafer, and J. Spilker, Z. Kristall., 1984, 168, 187-195.

73. S. Kek, M. GrotepassDeuter, K. Fischer, and K. Eichhorn, Z. Kristall., 1997, 212, 671-678.

74. H. Ratajczak, A. Muller, H. Bogge, J. Baran, and M. M. Ilczyszyn, Ferroelectrics, 1996, 177, 173-179.

75. K. Ruhlandtsenge, A. Bacher, and U. Muller, Z.Naturforsch., Teil B, 1992, 47, 1677-1680.

76. C. Lee and W. T. A. Harrison, Acta Crystallogr., Sect. C, 2007, 63, m308-m311.

77. H. Ratajczak, J. Barycki, A. Pietraszko, J. Baran, S. Debrus, M. May, and J. Venturini, J. Mol. Struct., 2000, 526, 269-278.

78. H. Wilkinson and W. Harrison, Acta Crystallogr., Sect. C, 2005, 61, m253-m255.

79. T. Fukami, Phys. Status Solidi A-Appl. Res., 1990, 121, 383-390.

80. T. Fukami, J. Phys. Soc. Jpn., 1989, 58, 3429-3430.

81. E. Fanchon, J. Vicat, D. Qui, and A. Boudjada, Acta Crystallogr., Sect. C, 1987, 43, 1022 1025.

82. H. Wilkinson and W. Harrison, Acta Crystallogr., Sect. E, 2005, 61, m2023-m2025.

83. J. Janczak and G. J. Perpetuo, Acta Crystallogr., Sect. C, 2008, 64, o330-o334.

84. H. S. Wilkinson and W. T. A. Harrison, Acta Crystallogr., Sect. E, 2006, 62, m1397-m1399.

85. C. Lee and W. Harrison, Acta Crystallogr., Sect. E, 2003, 59, m959-m960.

86. A. Oueslati and C. Ben Nasr, Anal. Sci. X, 2006, 22, x177-x178.

87. L. Andrade, M. Costa, J. Paixao, J. Moreira, A. Almeida, M. Chaves, and A. Klopperpieper, Z. Krist.-New Cryst. Struct., 1999, 214, 535-536. 
88. H. Wilkinson and W. Harrison, Acta Crystallogr., Sect. E, 2005, 61, m1228-m1230.

89. A. Zalkin, D. Eimerl, and S. Velsko, Acta Crystallogr., Sect. C, 1989, 45, 812-813.

90. I. Tordjman, R. Masse, and J. Guitel, Acta Crystallogr., Sect. C, 1988, 44, 2057-2059.

91. W.-T. Yu and M.-K. Lu, Jiegou Huaxue, 1992, 11, 9-.

92. A. Waskowska, S. Dacko, and Z. Czapla, Z. Naturforsch. Teil A, 2003, 58, 722-726.

93. S. Debrus, M. May, J. Barycki, T. Glowiak, A. J. Barnes, H. Ratajczak, and D. J. Xue, J. Mol. Struct., 2003, 661, 595-601.

94. H. Wilkinson and W. Harrison, Acta Crystallogr., Sect. E, 2004, 60, m1359-m1361.

95. A. Chtioui, T. Guerfel, L. Benhamada, and A. Jouini, J. Soc. Chim. Tunis, 2003, 5, 171-.

96. H. S. Wilkinson and W. T. A. Harrison, Acta Crystallogr., Sect. E, 2007, 63, m1610-m1612.

97. J. Fabry, R. Krupkova, P. Vanek, and I. Cisarova, Acta Crystallogr., Sect. E, 2001, 57, o349o352.

98. J. Fabry, R. Krupkova, and I. Cisarova, Acta Crystallogr., Sect. C, 2001, 57, 403-405.

99. H. S. Wilkinson and W. T. A. Harrison, Acta Crystallogr., Sect. E, 2007, 63, m900-m901.

100. H. S. Wilkinson and W. T. A. Harrison, Acta Crystallogr., Sect. E, 2007, 63, m26-m28.

101. M. J. Todd and W. T. A. Harrison, Acta Crystallogr., Sect. E, 2007, 63, m945-m947.

102. I. Tordjman, R. Masse, and J. Guitel, Acta Crystallogr., Sect. C, 1988, 44, 2055-2057.

103. J. Pecaut, Y. Lefur, and R. Masse, Acta Crystallogr., Sect. B, 1993, 49, 535-541.

104. A. Oueslati, A. Rayes, C. Ben Nasr, and F. Lefebvre, Mater. Res. Bull., 2005, 40, 1680-1689.

105. J. Fabry, J. Kroupa, and I. Cisarova, Acta Crystallogr., Sect. C, 2001, 57, 22-25.

106. H. Wilkinson and W. Harrison, Acta Crystallogr., Sect. E, 2005, 61, m1289-m1291.

107. A. Oueslati and C. Ben Nasr, Anal. Sci. X, 2006, 22, x1-x2.

108. A. Chtioui, L. Benhamada, and A. Jouini, Mater. Res. Bull., 2006, 40, 2243-2255.

109. M. Abdellahi and T. Jouini, Acta Cryst., Sect.C, 1996, 52, 1198-1200.

110. G. Ferraris, D. Jones, and J. Yerkess, Acta Crystallogr., Sect. B, 1971, B 27, 354-359.

111. G. Ferraris and G. Chiari, Acta Crystallogr., Sect. B, 1970, B 26, 1574-1583.

112. W. Baur and A. Khan, Acta Crystallogr., Sect. B, 1970, B 26, 1584-1596.

113. M. Todd and W. Harrison, Acta Crystallogr., Sect. E, 2005, 61, m1459-m1461.

114. C. Lee and W. Harrison, Acta Crystallogr., Sect. E, 2003, 59, m739-m741.

115. C. Lee and W. Harrison, Acta Crystallogr., Sect. E, 2003, 59, m1151-m1153.

116. M. Todd and W. Harrison, Acta Crystallogr., Sect. E, 2005, 61, m2026-m2028.

117. H. S. Wilkinson and W. T. A. Harrison, Acta Crystallogr., Sect. E, 2007, 63, m905-m907.

118. M. J. Todd and W. T. A. Harrison, Acta Crystallogr., Sect. E, 2005, 61, m1024-m1026.

119. T. Hseu and T. Lu, Acta Crystallogr., Sect. B, 1977, 33, 3947-3949.

120. B. Dickens and W. Brown, Acta Crystallogr., Sect. B, 1972, B 28, 3056-3065.

121. A. Ferrari, L. Cavalca, and M. Nardelli, Gazz. Chim. Ital., 1954, 84, 169-174.

122. C. Schneidersmann and R. Hoppe, Z. Anorg. Allg. Chem., 1991, 605, 67-74.

123. M. Mathew, J. Chem. Crystallogr., 1998, 28, 741-746.

124. H. Effenberger, Z. Kristall., 1998, 213, 42-46.

125. M. Weil, Cryst. Res. Technol., 2008, 43, 1286-1291.

126. J. Rius and S. Gali, Cryst. Struct. Commun., 1982, 11, 829-834.

127. J. Korp, I. Bernal, L. Avens, and J. Mills, J. Crystallogr. Spectr. Res., 1983, 13, 263-272.

128. A. Rheingold, M. Kane, and M. Fountain, Structure GORKAZ, Cambridge database, deposition CCDC 115079, 1999.

129. E. Irmer, G. Sheldrick, S. Parmar, and H. Saluja, Acta Crystallogr., Sect. C, 1988, 44, 2024 2025.

130. L. Shkolnikova, V. Fundamenskii, and A. Poznyak, Kristallografiya, 1992, 37, 684-691.

131. A. Terzis and P. V. Ioannou, Chem. Phys. Lipids, 2002, 117, 53-61.

132. A. Chatterjee and S. P. Sen Gupta, Acta Crystallogr., Sect. B, 1977, 33, 3593-3595.

133. R. Nuttall and W. Hunter, Acta Crystallogr., Sect. C, 1995, 51, 2342-2344. 
134. M. J. Percino, V. M. Chapela, T. Zayas, and C. R. de Barbarin, J. Chem. Crystallogr., 2002, 32, 307-314.

135. M. B. L. Marx, B. Nuber, and B. K. Keppler, Phosphorus Sulfur Silicon Relat. Elem., 1996, 118, 31-38.

136. M. Smith, R. Zingaro, and E. Meyers, J. Organomet. Chem., 1971, 27, 341-\&.

137. M. Zenki, T. Shibahara, M. Yamasaki, and Y. Kushi, Anal. Sci., 1990, 6, 153-154.

138. A. M. Herrera, J. Garcia-Serrano, J. G. Alvarado-Rodriguez, J. F. Rivas-Silva, and U. Pal, Acta Crystallogr., Sect. E, 2005, 61, M2752-M2754.

139. M. J. Percino, V. M. Chapela, C. Rodriguez-Barbarin, and S. Bernes, J. Mol. Struct., 2001, 562, 45-53.

140. V. Goedken, L. Brough, and W. Rees, J. Organomet. Chem., 1993, 449, 125-130.

141. V. Bel'skii, Kristallografiya(Russ.)(Crystallogr. Rep.), 1982, 27, 56.

142. E. J. Chan, J. S. Edmonds, K. Kazawa, B. W. Skelton, and A. H. White, Chem. Lett., 2007, 36, 160-161.

143. L. SilaghiDumitrescu, M. N. Gibbons, I. SilaghiDumitrescu, J. ZukermanSchpector, I. Haiduc, and D. B. Sowerby, J. Organomet. Chem., 1996, 517, 101-106.

144. N. M. Gresley, W. P. Griffith, A. J. P. White, and D. J. Williams, J. Chem. Soc.-Dalton Trans., 1997, 89-92.

145. W. Sheldrick and H. Häusler, Z. Anorg. Allg. Chem., 1987, 549, 177-186.

146. F. Jalilehvand, D. Spångberg, P. Lindqvist-Reis, K. Hermansson, I. Persson, and M. Sandström, J. Am. Chem. Soc., 2001, 123, 431-441.

147. V. Vchirawongkwin, B. M. Rode, and I. Persson, J. Phys. Chem. B, 2007, 111, 4150-4155.

148. Y. Marcus, Chem. Rev., 2009, 109, 1346-1370. 